\title{
Prevention of Avian Influenza Virus by Ultraviolet Radiation and Prediction of Outbreak by Satellite Parameters
}

\section{Tai-Jin Kim}

University of Suwon, Hwaseong, South Korea

Correspondence to: Tai-Jin Kim, tjkim@suwon.ac.kr

Keywords: Prevention, Avian Influenza Virus, Ultraviolet, Outbreak, Satellite

Received: May 24, $2018 \quad$ Accepted: July 23, $2018 \quad$ Published: July 26, 2018

Copyright $\odot 2018$ by author and Scientific Research Publishing Inc.

This work is licensed under the Creative Commons Attribution International License (CC BY 4.0).

http://creativecommons.org/licenses/by/4.0/

\section{(c) (i) Open Access}

\section{ABSTRACT}

The present study showed that avian influenza virus (AIV) occurred in the regions with rice and wheat productions under low ultraviolet (UV) radiation while there were negligible AIV outbreaks in the regions with a high rate of skin cancer due to extensive UV radiation. It is therefore proposed that having artificial UV radiation with poultry farmhouses is a simple solution to suppress AIV outbreaks. AIV outbreaks can be predicted a few months in advance by remote sensing satellite parameters such as Cosmos (minimum sunspot number, $10.7 \mathrm{~cm}$ solar flux, high UV radiation), Poles $\left(\mathrm{CO}_{2}, \mathrm{O}_{3}\right.$ hole deterioration, hydroxyl layer temperature, ice-melting, chlorophyll or algae, krill, penguin, guillemot), and Continents (migratory birds, desert dust, low UV radiation, waters, fish, rice and wheat, climate). Since there was an abrupt $2 \%$ rise of global $\mathrm{CO}_{2}$ emissions in 2017 , while the minimum sunspot number is simultaneously reached at the end of 2018, there can be an extensive UV radiation for mutant AIV in the Poles to have the highest degree of damage by AIV in regions such as U.S., East Asia, China, South Korea, Japan, west Africa, and Europe from November of 2018 till April of 2019.

\section{INTRODUCTION}

Avian influenza viruses (AIV) cause widespread morbidity and mortality in a broad range of hosts such as birds, swine, companion animals, marine animals, and humans. In the early 21 st century, anxiety over the danger of influenza A virus subtypes H5N1 (avian flu) and more recently H1N1 (swine flu) has revived memories of New Zealand's worst disease outbreak, the lethal influenza pandemic that struck between October and December 1918 (http://nzhistory.govt.nz/culture/influenza-pandemic-1918). One third of the world population died (as many as 20 to 50 million) while there was half a million deaths only in the 
United States, as summarized by The American Association for Clinical Chemistry in 2016. Influenza A viruses are roughly spherical $(80-120 \mathrm{~nm})$ with glycoprotein spikes on the surface and genome consisting of eight RNA fragments that encode 10 proteins. The haemagglutinin (HA), neuraminidase (NA) and matrix (M2) proteins are embedded in the envelope lipid bilayer derived from the host cell. Since there are currently $18 \mathrm{HA}$ and $11 \mathrm{NA}$ subtypes, 198 combinations with 4 strains of A, B, C and D [1] are thus available to suggest that AIV is hard to block for their cell-cell spread in advance whatsoever vaccination is developed. AIV are classified into two groups based on their overall pathogenicity to domestic chickens: low pathogenic avian influenza (LPAI) causes mild disease in poultry such as mucosal infection and a decrease in eggs; highly pathogenic avian influenza (HPAI) causes severe mortality often with rapid spread resulting in $100 \%$ flock mortality within 48 hours of exposure [2]. LPAI viruses occur in all HA and NA subtypes, but HPAI viruses have been restricted to H5 and H7 subtypes. One of the molecular causes for transition from LPAI to HPAI is the addition of amino acids at the HA cleavage site, which allows the virus to attack many different types of cells, causing systematic and often lethal infection within the host's body [3]. Since viruses should penetrate the host cells in order to cause infection, the prevention of viral entry, other than culling birds and poultry, is an attractive anti-viral strategy to minimize the chance of virus evolution and inactivate the viral viability at an early stage. There were HPAI H5N1 outbreaks in 1996 in Guangdong of China and nearby Hong Kong in 1997. There was the thinnest ozone layer in the Poles to provide the highest ultraviolet (UV) radiation in 1996. Such a high UV exposure during springtime (Sep.-Nov.) of Antarctica might mutate AIV in form of LPAI H5N1 and move migratory birds to the Continent to spread the mutated HPAI H5N1 in favorable environments.

AIV can remain infectious in water for months and virus-contaminated surface water is considered to be a source of infection within wild waterfowl populations. The duration of AIV persistence was determined to be the longest in filtered surface water with low temperature $\left(<17^{\circ} \mathrm{C}\right)$, neutral-to-basic $\mathrm{pH}(7.0$ to $8.5)$, low salinity ( $<5 \mathrm{ppt})$, and low ammonia concentration $(<0.5 \mathrm{ppm})[4]$.

Factors suppressing AIV are temperature, relative humidity, $\mathrm{pH}$, salinity, water, soil, rice, wheat, UV radiation, aquatic food web, desert dust, and migratory birds. Inactivation of the infectivity of HPAI H7N1 and $\mathrm{H} 5 \mathrm{~N} 1$ by environmental ultraviolet B flux $\left(90 \mu \mathrm{W} / \mathrm{cm}^{2}\right)$ took $158 \mathrm{~min}$ and $167 \mathrm{~min}$ for a reduction in titre of $1 \log _{10}$ median tissue culture infectious dose, respectively [5]. Airborne transmission appears to play a role in the spread of influenza, which may be reduced by $254 \mathrm{~nm}$ germicidal UV (UV-C) doses ranging from 4 to $12 \mathrm{~J} / \mathrm{m}^{2}$ [6]. Since poultry is one of the largest segments of agriculture with livestock and crops, the outbreaks of poultry diseases by AIV are critical to farm cash receipts. Chickens were primarily associated with AIV seropositivity compared to turkeys, ducks, guinea fowl and geese [2] while the persistence of AIV was determined by virus isolation in embryonated chicken eggs.

The present study provides artificial UV radiation at $254 \mathrm{~nm}$ for destruction of AIV of H9N2 and also relates to the prediction of AIV outbreaks based on data such as global carbon dioxide emissions, minimum sunspot number, $10.7 \mathrm{~cm}$ solar flux, hydroxyl layer temperature, ozone hole and UV radiation.

\section{RESULTS AND DISCUSSION}

\section{1. $\mathrm{CO}_{2}$ Increase}

Carbon dioxide $\left(\mathrm{CO}_{2}\right)$ absorbs and emits infrared radiation at wavelengths of $4.26 \mu \mathrm{m}$ and $14.99 \mu \mathrm{m}$ to be a greenhouse gas that plays a vital role in regulating Earth's surface temperature through the greenhouse effect. Ozone $\left(\mathrm{O}_{3}\right)$ protects the earth's surface from Sun's harmful ultraviolet radiation. $\mathrm{CO}_{2}$ increase with climate change expands and thins the ozone hole so that solar UV-B radiation is consequently increased to induce specific changes in lipid content and composition of Antarctic marine phytoplankton [8]. UV induced mutagenesis in the bacterium Deinococcus deserti [9]. Such a UV-B induced change effects virus, phytoplankton, zooplankton, krill, fish, and penguins. Migratory birds are in contact with AIV infected penguins while migratory birds under extensive UV-B radiation in summer feeding areas transmit LPAI AIV to winter breeding areas under low UV-B radiation in the Continental wetlands to infect to the poultry and humans with HPAI AIV. 
Marine mammals such as Baiji in China's Yangtze River dolphin (Figure 1(a), could be the carrier of AIV although functionally has been extinct since 2004 [10], presumably caused by the climate change due to the abrupt increase of Chinese Industry with enormous $\mathrm{CO}_{2}$ emission at the beginning of 2003, as shown in Figure 1(b). The ozone layer becomes thin under the abrupt increase of $\mathrm{CO}_{2}$ emissions to have the extensive UV radiation for strong AIV mutation. Significantly, the minimum sunspot number was recorded in 2006 (Table 1). Thus, the likely low sunspot number in 2003 means damage might have occurred to Baiji in 2003, causing them to be functionally extinct.

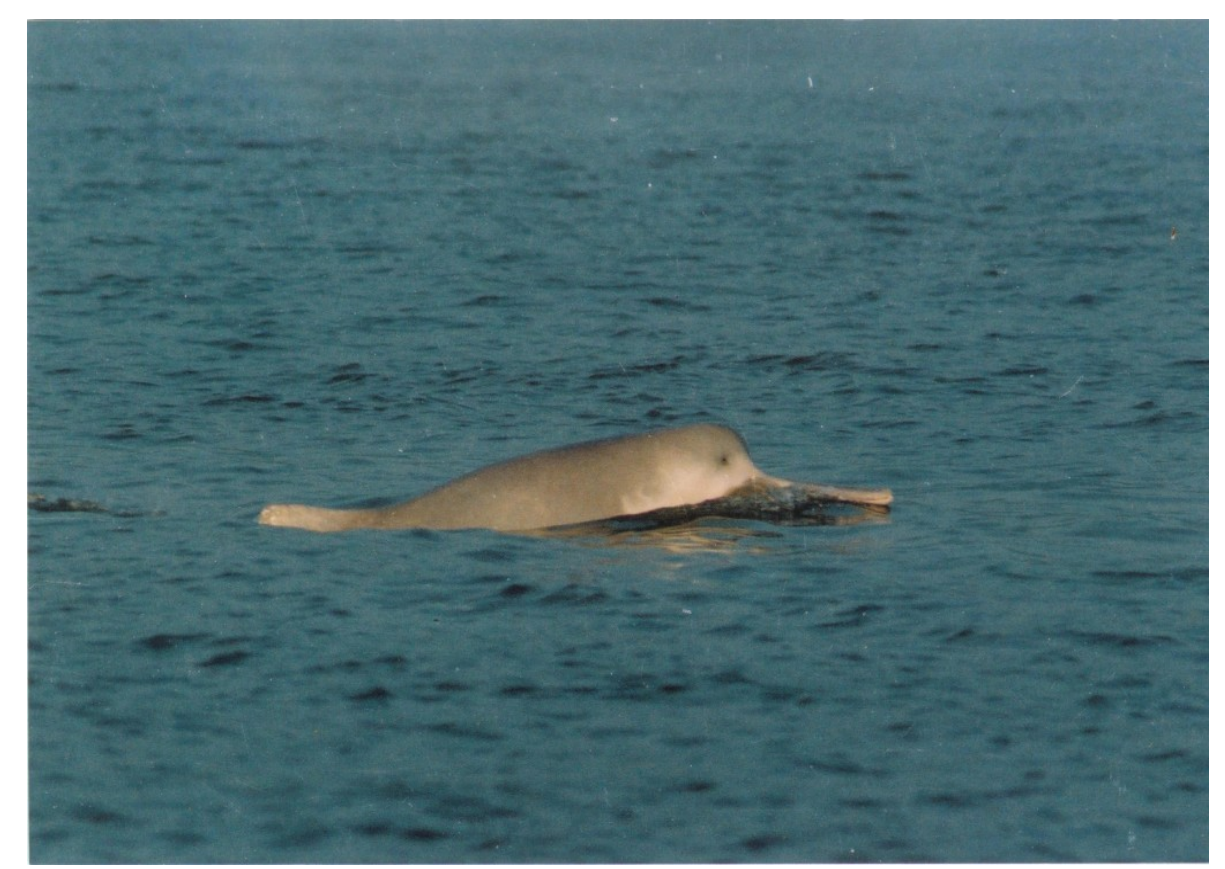

(a)

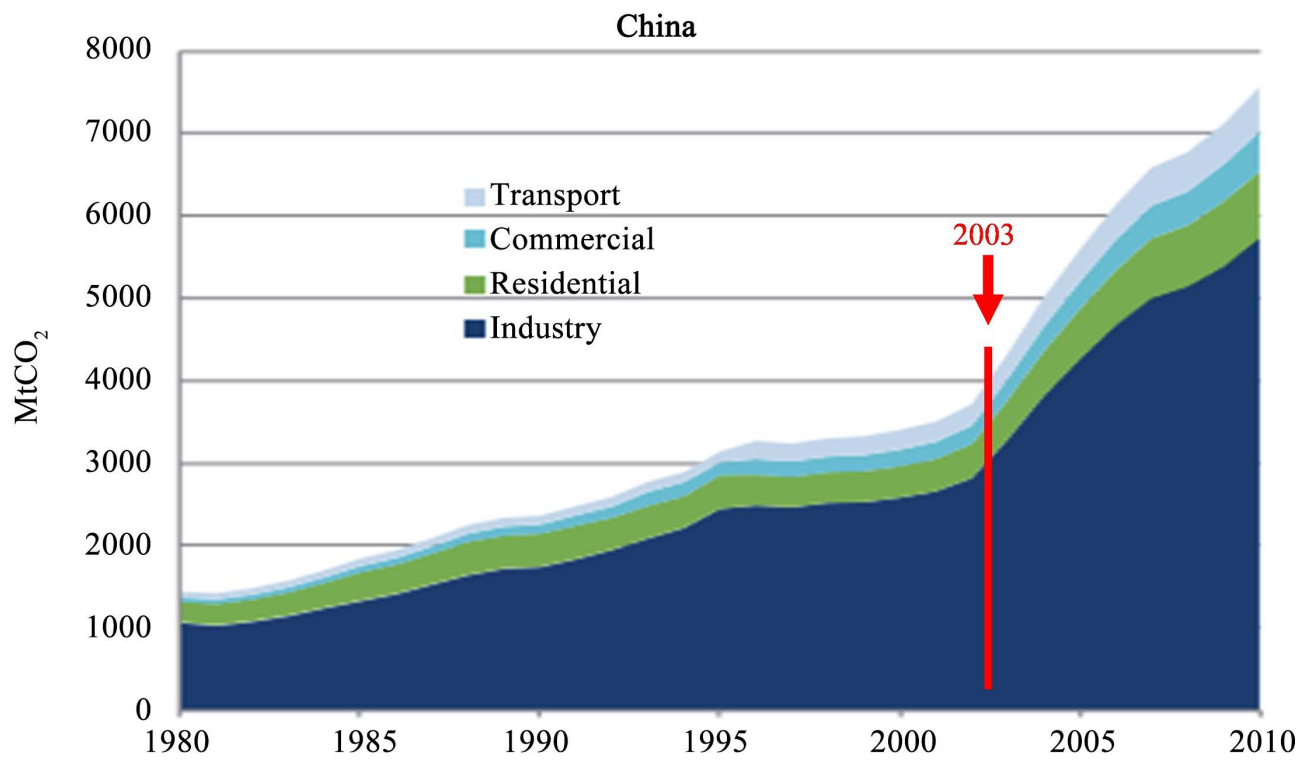

(b)

Figure 1. (a) A free-ranging Baiji swims in China's Yangtze River in this undated photo [10]; (b) China's energy-related carbon dioxide emissions (1980-2010). Sources: NBS, 2011; EIA, 2011. 
Table 1. Pandemics of influenza A and other important influenza events in the last one hundred years.

\begin{tabular}{|c|c|c|c|c|c|c|}
\hline $\begin{array}{l}\text { Year of } \\
\text { appearance }\end{array}$ & $\begin{array}{l}\text { Yearly global } \\
\text { carbon emission } \\
\text { rate }\left(10^{6} \text { ton } / y r\right) \\
(\text { CDIAC, } 2018)\end{array}$ & $\begin{array}{l}\text { Year of } \\
\text { minimal } \\
\text { average daily } \\
\text { sunspot area } \\
{[12]}\end{array}$ & $\begin{array}{l}\text { Virus subtype } \\
\text { [27] }\end{array}$ & Host & $\begin{array}{l}\text { Common } \\
\text { designation }\end{array}$ & $\begin{array}{l}\text { Estimated } \\
\text { deaths }\end{array}$ \\
\hline 1918 & 1000 & 1915 & $\mathrm{H} 1 \mathrm{~N} 1$ & Swine & Spanish & 100 million \\
\hline 1957 & 2000 & 1955 & $\mathrm{H} 2 \mathrm{~N} 2$ & Duck & Asian & 86,000 in the USA \\
\hline 1968 & 4000 & 1966 & $\mathrm{H} 3 \mathrm{~N} 2$ & Swine & Hong Kong & 34,000 in the USA \\
\hline 1997 & 6000 & 1996 & $\mathrm{H} 5 \mathrm{~N} 1$ & Goose & $\begin{array}{l}\text { Chicken } \\
\text { or bird }\end{array}$ & $\begin{array}{l}148 \text { deaths from } \\
2003 \text { until October } \\
2006\end{array}$ \\
\hline 2004 & $\begin{array}{l}3200 \text { (China) } \\
7812 \text { (World) }\end{array}$ & 2006 & - & $\begin{array}{l}\text { Baiji } \\
\text { dolphin }\end{array}$ & Yangtze River & $\begin{array}{l}\text { Yangtze River Bai- } \\
\text { ji dolphin } \\
\text { extinct }\end{array}$ \\
\hline 2013 & $9740(2012)$ & 2015 & H11N2 [13] & $\begin{array}{l}\text { Adélie } \\
\text { Penguin }\end{array}$ & $\begin{array}{l}\text { Petrels Island, } \\
\text { Antarctic } \\
\text { Peninsula }\end{array}$ & $\begin{array}{l}\text { 20,196 pairs, no } \\
\text { chicks survived } \\
{[14]}\end{array}$ \\
\hline 2017 & 10,000 & 2018 & H5N5 [13] & $\begin{array}{l}\text { Adélie } \\
\text { Penguin }\end{array}$ & $\begin{array}{l}\text { East } \\
\text { Antarctica }\end{array}$ & $\begin{array}{l}\text { 40,000 Adélie } \\
\text { Penguin deaths } \\
{[15]}\end{array}$ \\
\hline
\end{tabular}

As recently as the 1950s, there were an estimated 5000 Baiji living in China's Yangtze River. Two years later, after a broad survey failed to find a single animal, the species was declared "functionally extinct." The Yangtze River crosses the wide land of China from the left side to the right side of Shanghai. The shallow lake wetlands in the middle and lower Yangtze River floodplain are important wintering and stop-over habitats for migratory waterbirds on the East Asia-Australia Flyway from November 2006-April 2008 and from November 2008-April 2009. The Caize Lake and Shengjin Lake along the Yangtze River from Nov. 2007 to April 2009 showed wintering water birds (geese, swan, dunlin) reaching maximum at the end of December and in early January of the following year [11] while there were AIV outbreaks in South Korea during the same period.

Although the Yangtze River dolphine seems to have disappeared, there are still mudfish, catfish, lungfish, and bullfrog, forming the reservoir of AIV transmitted by fecet of migratory birds. It is most likely that China is the main source of AIV outbreaks due to good habitats of AIV with rice production, lakes, rivers, climate, rainfall, low UV radiation, human population, fishes, wetlands, tidal mud flat, stop-over site, desert dust, and air pollution with high $\mathrm{CO}_{2}$ from combustion of fossil fuels. Therefore, without controlling the Chinese source of the spread of AIV, it is meaningless to suppress the AIV outbreak in all over the world.

Over the past 150 years at least four pandemics of influenza occurred at irregular intervals, including three in the 20th century (Table 1). These have caused high morbidity and mortality. The most lethal in- 
fluenza pandemic in modern history was the H1N1 Spanish flu, which killed approximately 100 million people around the world between 1918 and 1919. The origin of the 1918 pandemic remains an enigma, but it is now clear that the virus had features of an avian virus, and it appears that an intermediate host, such as swine was involved. Swine are known to be susceptible to both avian and human viruses, and could have served as hosts for additional drift resulting in the accumulation of changes from the original avian strain. It's important to analyse the environmental conditions in Spain from 1918-1919. Catalunya with its textile industry and Altos Hornos de Vizcaya with its steel foundry built in 1902 produced $\mathrm{CO}_{2}$ in Spain. Increased $\mathrm{CO}_{2}$ concentration induced thin ozone layer while thin ozone layer caused the increases of UV radiation and temperature. Temperature increase enhanced the ice-melting in Poles to decrease algae beneath the ice so that penguins starved weakening their immunity and making them vulnerable to an AIV outbreak transmitted by migratory birds. Spain is located as a stop-over of three migratory bird flyways; East Atlantic, Black Sea/Mediterranean, and East Africa/West Asia. Therefore, there could have been frequent chances of contact between AIV infected migratory birds and wild domestics birds, the latter being contaminated to transmit HPAI to poultry and humans without immunity against HPAI to cause enormous deaths of humans in 1918 (Table 1). Furthermore, there is Saharan Aeolian input over western Europe [16] including Iberian Peninsula of Spain from North Africa. Aeolian particles carried bacteria [17] and thus AIV could be hosted by such bacteria to transmit AIV via the stream of Saharan Aeolian input to Spain. During the Second Industrial Revolution, three countries became the world's biggest industrial producers of $\mathrm{CO}_{2}$; the United States, Germany and Great Britain. It can be suggested that the 1918 Spain flu pandemic (1918-1920), which resulted in the deaths of 50 to 100 million, was caused by the increases of $\mathrm{CO}_{2}$ production during the Second Industrial Revolution (1870-1914) and the First World War (1914-1918), whereas the thin ozone layer was made due to $\mathrm{CO}_{2}$ increase. Such a thin ozone layer allowed the extensive UV radiation in Poles to have mutant LPAI AIV. Migratory birds contacting with penguins and guillmots transmitted LPAI AIV to Continental Spain to be mutated as HPAI H1N1 in the favorable environment (cold temperature, low humidity, basic $\mathrm{pH}$, low salinity, food, low UV radiation) during October and December 1918. Environmental parameters associated with AIV outbreak were summarized in Figure 2 to show their relationships. Table 1 implies very important findings such as the abrupt increase of global carbon dioxide emissions from fossil fuel combustion causes the thin ozone hole while the minimal average daily sunspot area allows the maximal UV radiation in the Poles periodically. The minimum sunspot number is measured at Brussels in Belgium and Ottawa/British Columbia of Canada. UV exposure at the surface has been measured by direct instruments on the ground and by satellite of NASA's Total Ozone Mapping Spectrometer (TOMS) since 1978. Therefore, in the years when carbon dioxide combustion emission is high simultaneously at the minimal average daily sunspot area, the UV radiation on the surface of the Poles is so extensive to mutate aquatic virus through the food web eventually infecting penguins in the Antarctic or guillemot in the Arctic as LPAI until transmitted by migratory birds to the Continents as LPAI/HPAI or finally HPAI to poultry and humans. During either the increase of global $\mathrm{CO}_{2}$ emissions by fossil fuel combustion or the proximity to the minimal sunspot area there are increases of ozone hole deterioration to cause extensive UV radiation, which induce mutant virus infected prey (bacteria, phytoplankton, zooplankton, krill, small fish, squid) and predator (penguin, migratory bird) with LPAI in the Poles and LPAI/HPAI in the Continents with exchange of AIV remaining infective for 30-207 days in water [18] among rice, wheat, domestic poultry and migratory waterbirds.

\subsection{UV Radiation}

Biological action spectra are commonly used to assess health and ecosystem responses to increases in spectral ultraviolet (UV) irradiances resulting from stratospheric ozone $\left(\mathrm{O}_{3}\right)$ reductions [19]. The stratospheric ozone layer depleted by chlorofluoro carbons (CFCs), shields the earth from harmful UV-B radiation. There are ultraviolet (UV) with UV-A (315 - $400 \mathrm{~nm})$, UV-B $(280-315 \mathrm{~nm})$, UV-C (200-280 nm), Vacuum-UV (100 - $200 \mathrm{~nm})$, which are mostly absorbed by the ozone layer while part of UV-A and UV-B 


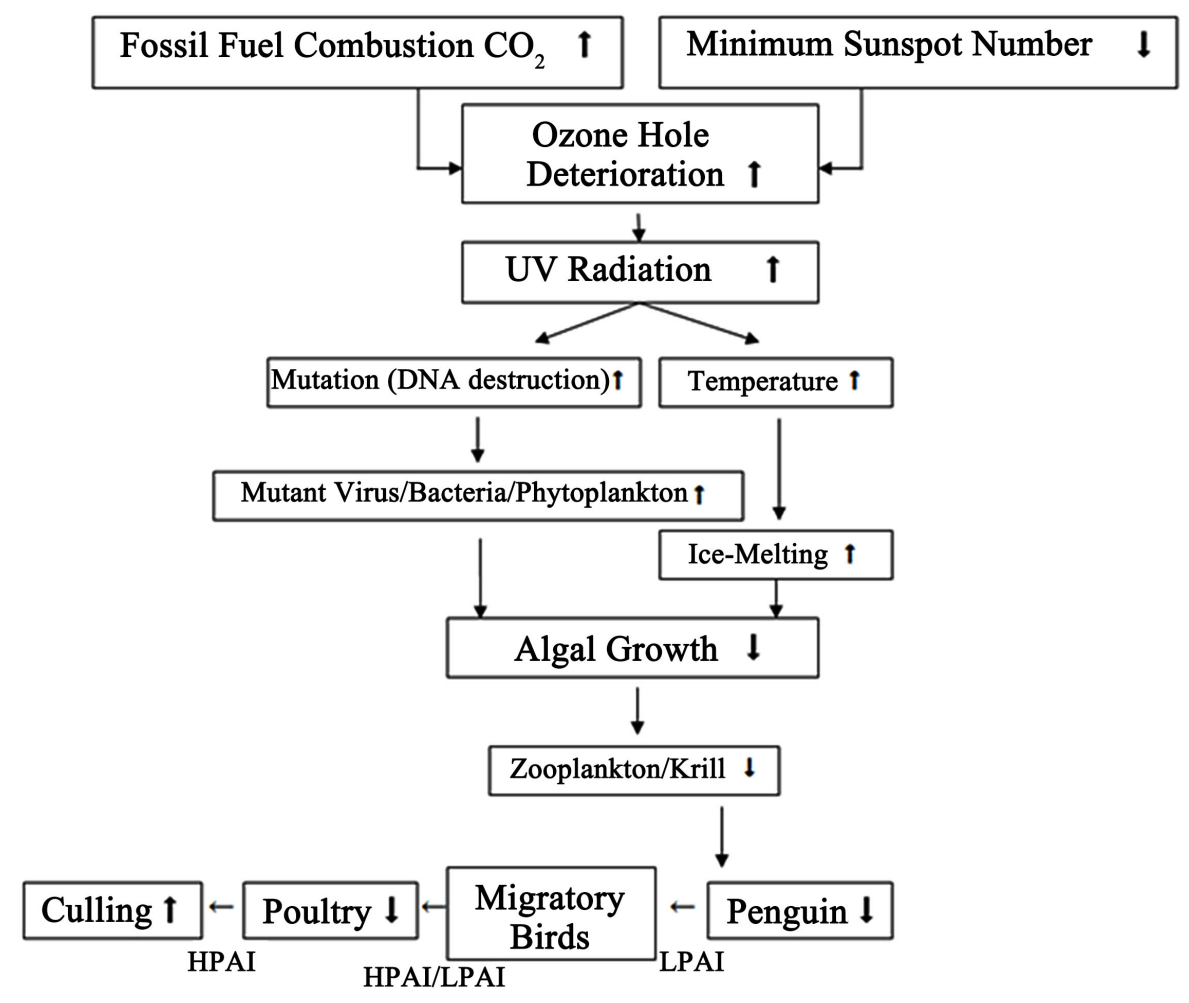

Figure 2. Flow diagram of environmental parameters associated with AIV outbreak ( $\uparrow$; increase, $\downarrow$; decrease).

radiate on the Earth. UV-C is completely absorbed in the upper atmosphere and used to sterilize the air and the water. There are NOAA Antarctic UV monitoring networks at three stations: South Pole Station, McMurdo Station, and Palmer Station equipped with Radiometers, whose data are collected every 15 minutes and processed into daily UV products (https://www.esrl.noaa.gov/gmd/grad/antuv/). An increase in the amount of UV radiation reaching the surface of the earth could have significant negative effects on human health, plants, and aquatic ecosystems. UV radiation acts as a natural environmental virucide because it causes photodimer formation between the pyrimidine bases in DNA and RNA, resulting in conformational changes that interrupt the viral replication process [5]. The most significant human health effect is an increase in the incidence of skin cancer. Skin cancer implies that skin's DNA has been damaged by strong UV radiation. Satellite instruments provide us with daily images of the ozone over the Antarctic region. The massive hole in the ozone hole layer, normally situated over Antarctica, is moving towards the South American countries to increase UV radiation causing skin cancer in Chile

(https://www.news24.com/Green/News, 2014). The Earth's ozone layer has left Chile with some of the highest skin cancer rates in the world [20]. The U.S. Environmental Protection Agency (EPA) estimates that a one percent decrease in the ozone could result in a two percent increase in UV-B, and a one percent increase in UV-B could result in a two to five percent increase in the rate of non-melanoma skin cancers. In addition, increased UV-B may also result in an increase in the rarer but more deadly malignant melanoma skin cancers. Other potential health effects include suppression of the immune system leading to a higher incidence of some infectious diseases, and eye disorders such as cataracts or retinal damage [21].

It is interesting to note that the global distribution of skin cancer death rates per 100,000 by country induced by UV-B radiation (Figure 3(a) is almost the opposite to that of HPAI H5N1 outbreaks (Figure 3(b). The 10 countries that have the highest rate of skin cancer are as follows: 1) New Zealand, 2) Australia, 3) Slovenia, 4) Norway, 5) Latvia, 6) Macedonia, 7) Denmark, 8) Croatia, 9) Netherlands, 10) Sweden, where there have been no noticeable outbreaks of HPAI H5N1 Figure 3(b). 


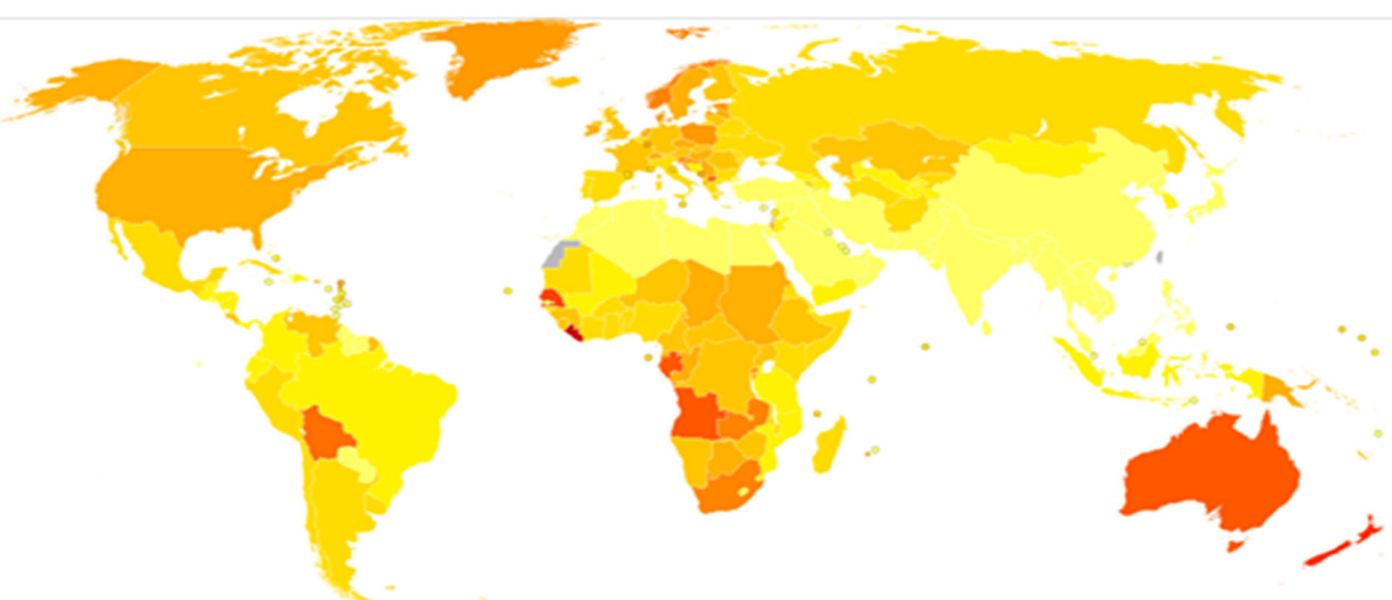

(a)

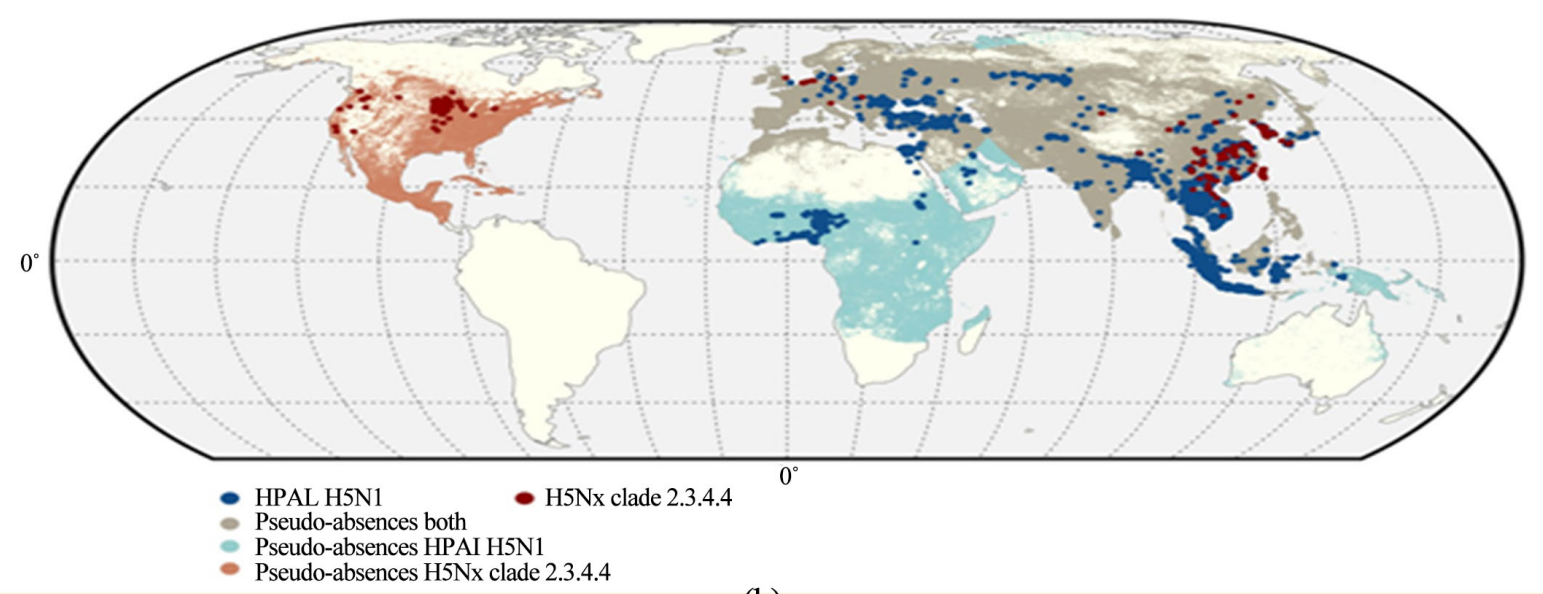

(b)

Figure 3. Distributions of (a); skin cancer induced by UV-B radiation [7] and (b); HPAI H5N1 outbreaks [22].

Such an opposite natural phenomena can be explained by the fact that the thin ozone hole in the Poles induces extensive UV radiation exposure causing skin cancer in countries (Figure 3(a) near Poles while there are negligible HPAI H5N1 outbreaks in New Zealand, Australia, South America, southern Africa, Greenland, northern Canada, northern Russia, and Scandinavian countries (Figure 3(b) due to the extensive UV exposure being enough to suppress AIV viability by destruction of its DNA structure. It can be proposed that the outbreaks of AIV infection and transmission in poultry farmhouses are suppressed by the appropriate UV radiation where there is artificial UV exposure to indoor aerosol route, drinking water, equipment and facilities.

The climate change induced by atmospheric increases of $\mathrm{CO}_{2}$ cause the ozone depletion with the increases of harmful ultraviolet radiation and subsequent increases of contents in Antarctic phytoplankton [8].

Maximal solar UV irradiance in wavelength 220 - $310 \mathrm{~nm}$ generating ozone $\mathrm{O}_{3}$ below $242 \mathrm{~nm}$, showed the minimal ozone holes in the spring seasons (September - October) in Antarctica [23]. Therefore, birds may start to migrate to Continents with mutant AIV induced by maximal solar UV irradiation in the Poles during the minimal average daily sunspot area.

The large ozone hole in the Antarctic lasts only from September to December to increase the expo- 
sure to UV-B radiation causing mutation in DNA, suppressing the immune system and reducing the productivity of phytoplankton in aquatic ecosystems

(https://www.nasa.gov/topics/solarsystem/features/uv-exposure.html).

The decay of the ozone hole in Antarctic spring is proceeded by the maximal solar UV irradiation with the regular 27-day variation [23]. New Zealand and Australia have the highest rate of skin cancer due to UV irradiation near thin ozone layer from Antarctica. The ozone layer absorbs UV-B (315 - $280 \mathrm{~nm})$ UV light from the Sun while UV-A (400 - $315 \mathrm{~nm}$ ) is not absorbed by the ozone. Any decrease in the ozone layer (such as ozone $\left(\mathrm{O}_{3}\right)$ hole over Antarctica) is expected to increase surface UV-B levels (https://www.sciencelearn.org.nz/resources/1329-nz-skin-cancer-statistics). The minimal period of the average daily sunspot area may cause the decrease of the $\mathrm{O}_{3}$ hole over Antarctic and Arctic zones. Such two Poles are analogous to the laboratory clean bench with UV (300-250 nm) exposure for sterilization and mutation of microorganisms. Therefore, each Pole causes low pathogenic virus rather than highly pathogenic virus due to extensive UV exposure in each Pole. New H5N1 or strains of AIV may be developed in penguins in Antarctica and guillemot in Arctica to be transmitted to Continents by breeding migratory birds during late spring of Antarctica, whose LPAIV may be transformed as HPAIV in Continents in friendly environments such as low UV-B, low temperature, low salinity, low relative humidity, and high desert dust with host cell bacteria for LPAIV and nutrients minerals enabling the strong viability of enzyme activity to transform from LPAIV to HPAIV.

The average area of the Antarctic ozone hole was changed in September in the years of $1994(20.5 \times$ $10^{6} \mathrm{~km}^{2}$ ), 1995 (11.1), 1996 (20.1), 1997 (18.3), 1998 (25.3), 1999 (21.4), 2000 (25.0), 2001 (23.0), 2002 (10.8), 2003 (25.8), while the $10.7 \mathrm{~cm}$ solar flux index showed the minimum in the year of 1995 [24]. Sunspot area or sunspot number as a function of time between years of 1870 and 2020 were shown in Figure 4 [12]. The average area of the Antarctic ozone hole was the smallest in 1995 and the $10.7 \mathrm{~cm}$ solar flux index showed the minimum. Besides, the minimum sunspot number is proportional to the $10.7 \mathrm{~cm}$ solar flux [12]. Therefore, there was a strong HPAI H5N1 in Hong Kong during 1995-1996. It can be postulated that there can be an AIV outbreak when there are either the smallest ozone hole or the minimum sunspot number.

The ozone hole reaches its annual maximum in September or October, at the end of winter in the Southern Hemisphere (NASA, 2017). It is likely that migratory birds are infected either in LPAI form or in mutant AIV by strong UV-B radiation in the Poles. When such infected birds move to the Hemispheres, there can be an HPAI spread due to weak UV-B radiation and enough feeding of rice/wheat, wetland, mineral-enriched desert dust in favorable environments (low temperature, low relative humidity, low salinity), similar to those of Antarctic Peninsula or sub-Antarctica with penguins.

Atmospheric ozone absorbing UV radiation is of considerable importance while the UV changes have been influenced by changes in aerosols, clouds, surface reflectivity and solar activity [25].

The ozone hole is defined as the area having less than 220 Dobson units of ozone to induce the Sun's harmful ultraviolet radiations in south Africa, southern South America, New Zealand and Australia. Total

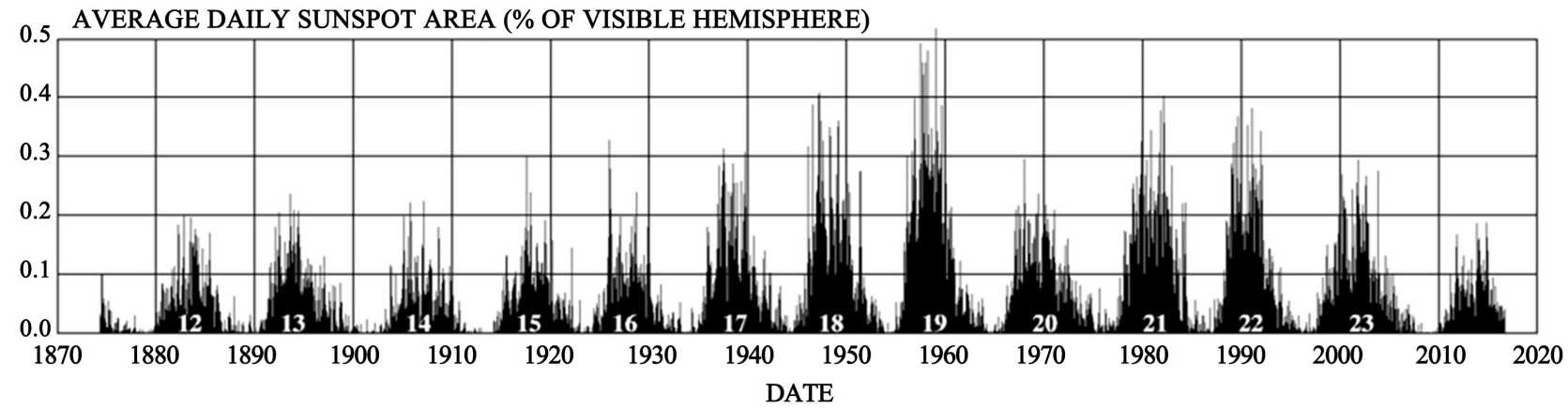

Figure 4. Sunspot area as a function of latitude and time [12]. 
ozone $\left(\mathrm{O}_{3}\right)$ over Antarctic during October has been decreasing since 1960, as shown in Figure 5. Correspondingly, UV-B radiation has increased to induce the mutations of virus and algae, the latter being fed on by penguins. As penguins are birds, they can hold mutated virus in form of LPAI AIV due to extensive UV-B exposure in the Poles. Such a mutated LPAI AIV is transmitted to the Continents by migratory birds from both of South and North Poles. Extensive UV-B radiations in Poles have been proved by the occurrences of skin cancers in New Zealand, Australia, southern South America, South Africa, Scandinavian countries, Denmark, northern Russia, and northern Canada while there were negligible outbreaks of AIV H5N1 in such areas. Frequent outbreaks of AIV H5N1 were observed in China, South Korea, Japan, East Asia, U.S.A. where there are many wetlands, mud flats, sufficient rice/wheat productions and farmlands, low salinity in drinking water, relative low $\mathrm{pH}(<8.2)$, and most importantly low UV-B radiation in favorable environments for outbreaks of HPAI AIV.

The simple method to control the outbreak of AIV in the poultry farmlands is then to apply the artificial UV-B radiation to the aerosol and the drinking water of indoor poultry farmhouses so that the viral persistence and activity of AIV are suppressed by UV-B radiation. Since the ozone over Antarctic decreases with years (Figure 5), UV radiation may increase with time in the Antarctic. Therefore, there can be more chances of mutant AIV due to the increase of UV radiation as years go on.

Germicidal UV generator (UV-254 nm) $\left(1.7 \mathrm{~W}\right.$ ) for the area $300 \mathrm{ft}^{2}$ per unit was used in Figure 6(a). Each UV-254 nm generator was stepwise turned on to see the efficiency of sterilization of H9N2 as increasing the number of UV germicidal generators. The result was drawn in Figure 6(b). Five sterilization kits were good enough to sterilize $99 \%$ for the area of $1800 \mathrm{ft}^{2}$.

Sterilization of drinking water UV sterilization apparatus (Figure 7(a)) was used to sterilize drinking water with serial experiments (Figure $7(b)$ ) to see that no colony of observed below $60 \mathrm{~L} / \mathrm{min}$ microorganism while recycle loop showed better efficiency of sterilization than that of common one for efficient sterilization of drinking water.

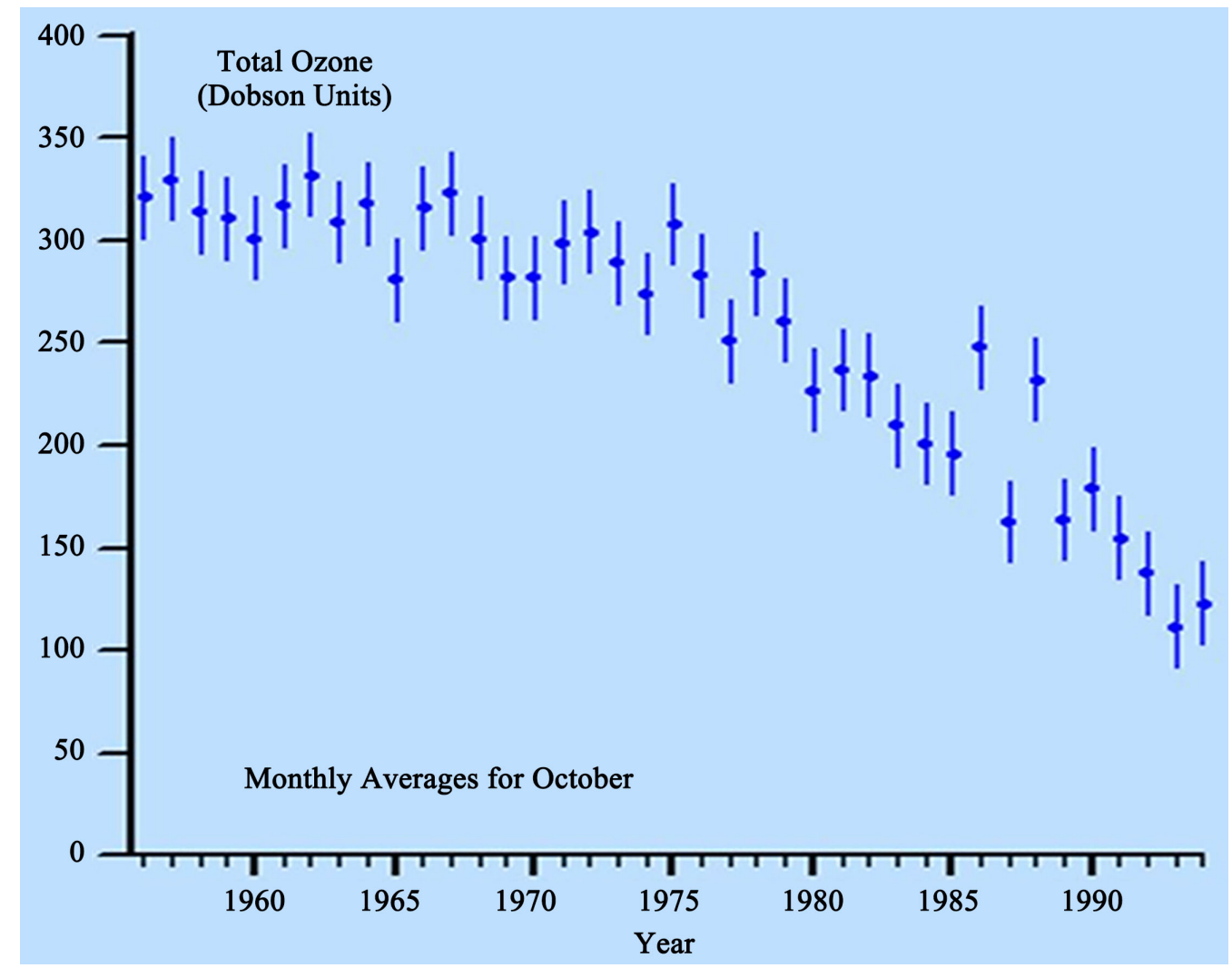

Figure 5. Ozone over Antarctic during October in years of 1955 to 1995. 


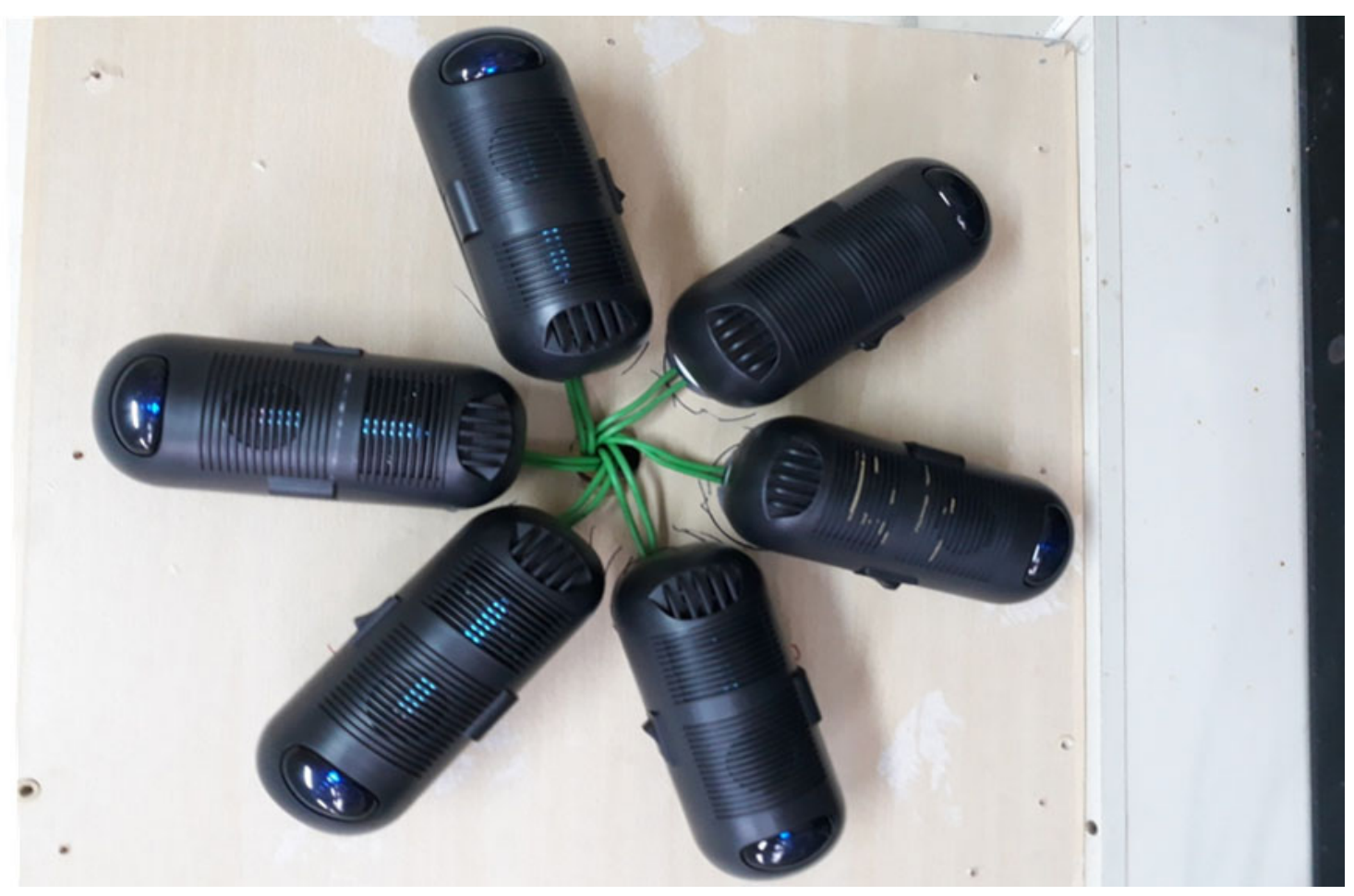

(a)

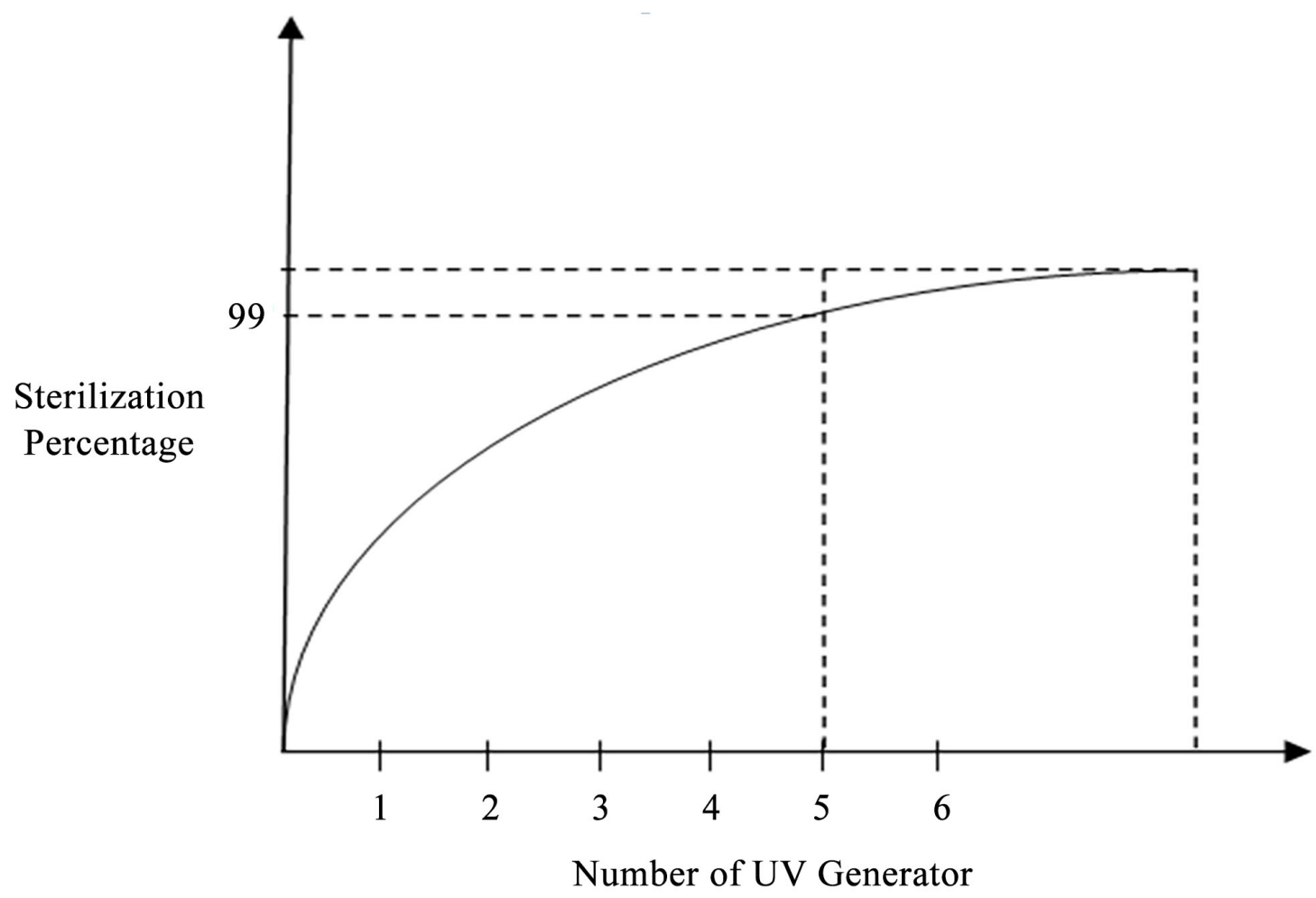

(b)

Figure 6. (a) Hexagonal arrangement of six UV germicidal generators for measurement of sterilization efficiency of H9N2 with the increased number of UV generators; (b) Distribution of sterilization percentage with germicidal UV-254 $\mathrm{nm}$ generator. 


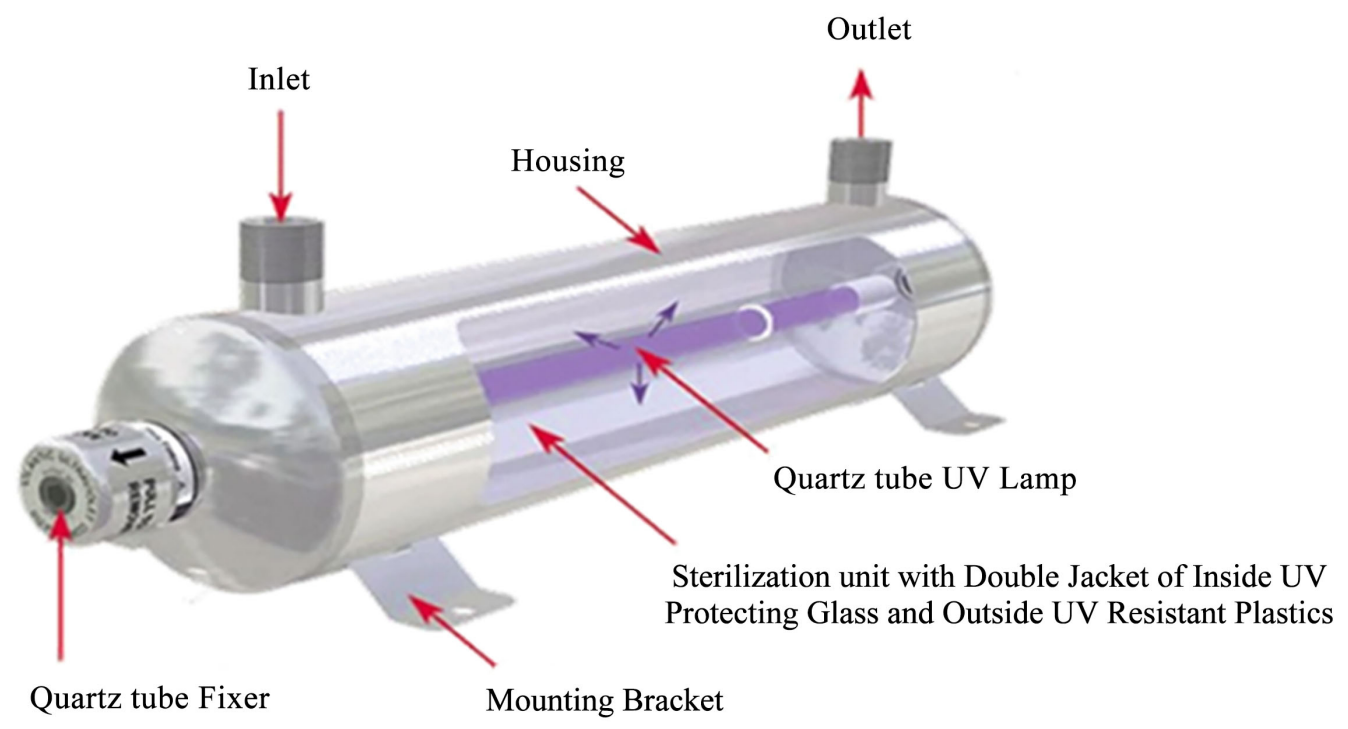

(a)

Common Recycle

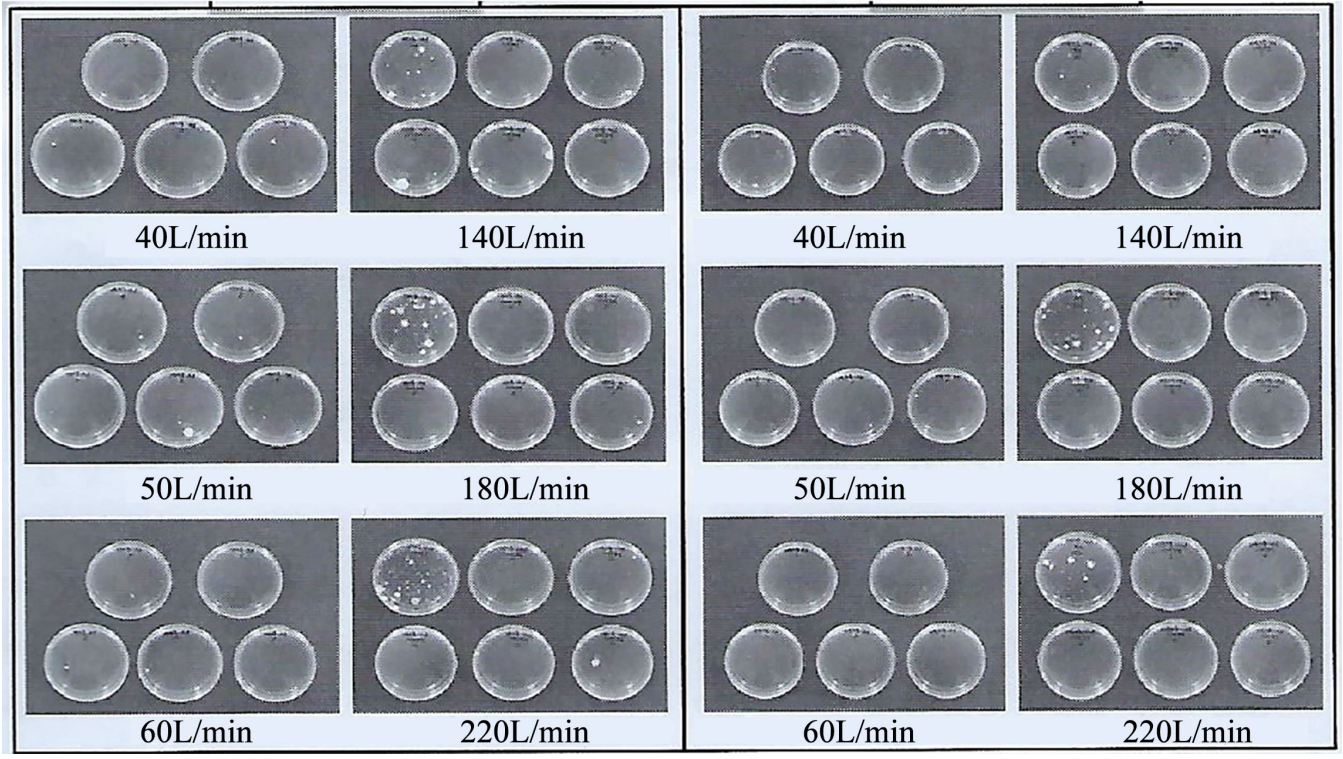

(b)

Figure 7. (a) Layout of tube for drinking water by UV sterilization apparatus; (b) Microorganisms in culture dishes for samples with various flow rates in the UV sterilization apparatus. The results showed that the flow rate below $60 \mathrm{~L} / \mathrm{min}$ was required for free microorganisms in drinking water under UV sterilization apparatus.

\subsection{HPAIV Outbreak}

The first case of HAPI in wild birds occurred in terns in South Africa in 1961 prior to the appearance of HPAI H5N1 in wild birds in Hong Kong in 2002 [26]. The first HPAI H5N1 was isolated from a goose in Guangdong in China in 1996. In 1997, outbreaks in humans and poultry in Hong Kong originated in live poultry markets. Hundred of millions of poultry have died from infection and culling practices and 596 human cases (350 deaths) have been confirmed since 2003 [27]. 
The result of sunspot area with years [12] implies that artificial UV-B irradiation on the poultry farmland; namely their equipment, food, water, and air may suppress the activity of AIV for blockage of its outbreak during the period of September to April when migratory birds move from Poles to the Continental poultry. Two primary avian reservoirs of AIV have been identified including the Anseriformes (ducks, geese, and swans) and the Charadriiformes (shorebirds and gulls), which have been detected in low pathogenicity infected wild birds. There are many strains of HPAI HxNy (Table 2) while " $x$ " and " $y$ " are varied depending on countries and years of outbreaks, presumably due to different HPAIV environments (route of flying birds, kind of migratory birds, source of North and South Poles, temperature, humidity, $\mathrm{pH}$, kind of prey (rice, wheat, corn, bullfrog, mudfish, catfish, lungfish), domestic wild birds, wetlands, and intensity of UV radiation.

The period of January to March is generally considered the peak of the HPAI H5N1 season, when outbreak numbers increase following an active period of disease events/reports (October to December) (EMPRES/FAO-GLEWS, 2012), as shown in Figure 8.

\subsection{Rice, Wheat and HPAI H5N1 Outbreak}

AIV is detected in water, sediments and ice, where mudfish, catfish, lungfish and small fish are habitable. Rice and wheat live in wetlands with sufficient water. Therefore, it is likely that wild migratory birds stay at wetlands to eat AIV infected fishes, rice and wheat. Rice paddy fields form the important wetland habitat for wild waterfowls or migratory birds, thus increasing the chances of HPAI virus transmission to and from the domestic poultry [19]. There were close relations between rice production, HPAI H5N1 outbreak under low water temperature, poultry, and migratory birds [18].

Table 2. List of country with various HPAIV outbreak in 2016 (http://jnana.tistory.com/822).

\begin{tabular}{cc}
\hline Virus & Country \\
H5 & Palestine, Russia, Tunisia, Ukraine, Bulgaria, Slovakia \\
H5N1 & China, France, Ghana, India, Iraq, Laos, Lebanon, Myanmar, Niger, Nigeria, Togo, \\
Vietnam
\end{tabular}




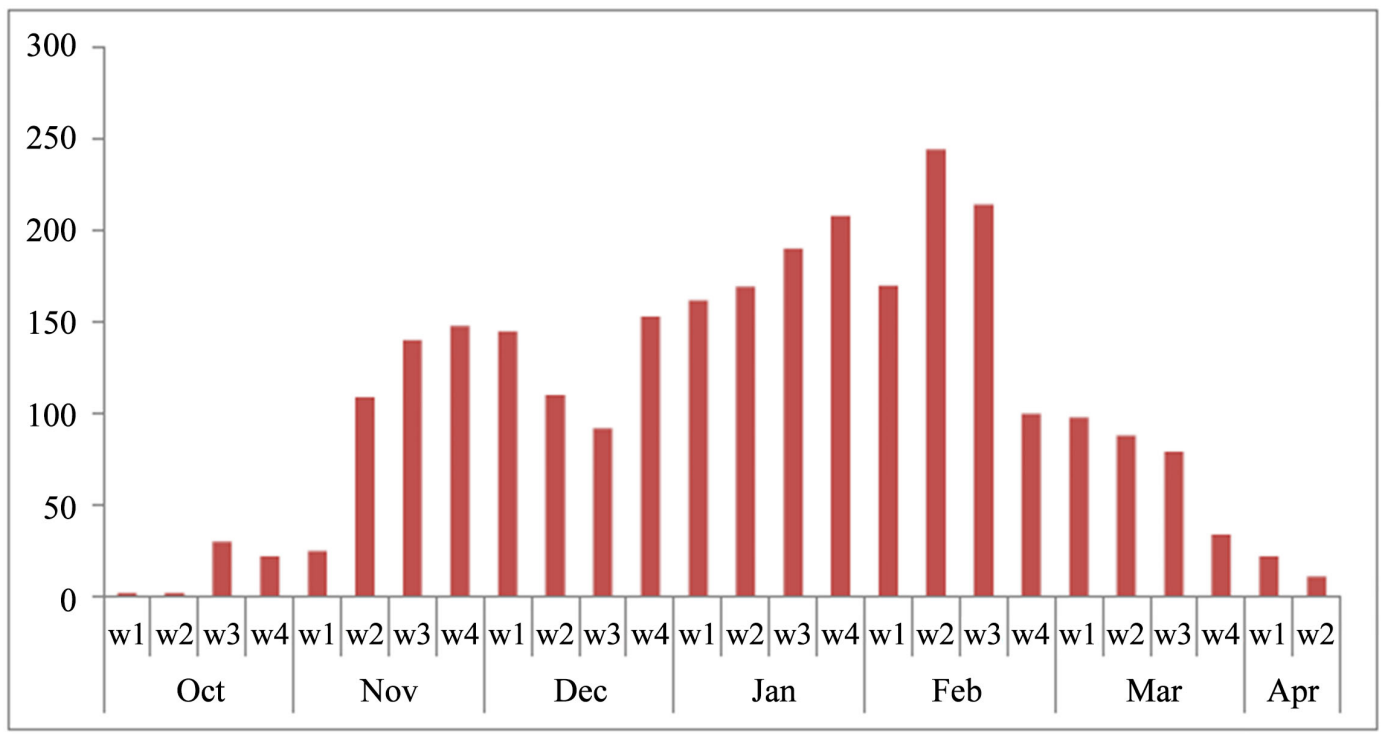

Figure 8. Epidemic curve showing the weekly incidence of outbreaks of HPAI since October 2016 (World Organisation for Animal Health, 2017).

There are countries with rice trades above half million tons per year of 2016 as; Asia (Burma, Cambodia, India, Pakistan, Thailand, China, Indonesia, Iran, Iraq, Malaysia, Philippines, Saudi Arabia, Japan, Korea, United Arab Emirates), Europe (European Union), Africa (Cote d'Ivoire, Nigeria, Senegal, Cameroon, Ghana), North America (United States, Cuba, Haiti, Canada) [28]. The main region to reduce the outbreaks of AIV can be Burma, Cambodia, China, India, Pakistan, Thailand and United States with a few millions tons of rice production per year while rough rice in harvesting fields of paddy lands is a good food for migratory birds. The superimposed map of rice and wheat production distributions (Figure 9 (c)) are in good agreement with that of HPAI H5N1 outbreaks (Figure 9(d)).

The maps of HPAI outbreaks [21] in poultry and wild birds (Figure 9(d)) is similar to the combined map of rice and wheat producing areas (Figure 9(c)). There are white parts in Figure 9(d) with regions such as 1. Australia and New Zealand, 2. southern Africa, 3. Sahara deserts 4. South America, 5. northern Canada and Alaska, where HPAI H5N1 outbreaks have been suppressed by strong UV radiation due to deterioration of ozone holes in Antarctica and Arctica. It is evident that artificial UV radiation is the key solution to suppress the outbreak of AIV. Since the migratory birds fly from Poles to Continental rice paddy and wetlands having rice, wheat, mudfish, catfish, lungfish, and bullfrog in mud with AIV persistence, the outbreaks of AIV have occurred in the areas of rice and wheat productions (Figure 9(a) and Figure $9(\mathrm{~b})$ ). It appears that the rice land is infected by migratory birds with LPAI and transmitted to poultry farmhouses in the form of HPAI to infect and kill poultry. AIV is an important public health issue because pandemic influenza viruses in people have contained genes from viruses that infect birds. The H5 and H7 AIV subtypes (Table 2) have periodically mutated from low pathogenicity to high pathogenicity form [29]. Figure 10 shows the AIV outbreaks of United States in wild birds in the order of Plains > Southeast $>$ Great Lakes $>$ Southwest $>$ Rocky Mountains $>$ Far West $>$ Northeast, which implies that AIV was frequent in areas associated with waters and cropland. As for states of AIV outbreaks are in the order of $\mathrm{MN}>\mathrm{IA}>\mathrm{TX}>\mathrm{IL}>\mathrm{NE}>\mathrm{KS}>\mathrm{IN}>\mathrm{MO}>\mathrm{SD}>\mathrm{OH}>\mathrm{ND}>\mathrm{KY}>\mathrm{WI}>\mathrm{CA}>\mathrm{MI}>\mathrm{GA}>\mathrm{TN}>\mathrm{VA}$, it is better to examine the present means of artificial UV radiation to measure and control AIV outbreaks in the areas of Plains (1012), especially in MN (250) and IA (196). Once effective, such prevention can be stepwise expanded to TX (162) of Southwest (232) and IL (160) of Great Lakes (501) to control AIV outbreaks in US states (2699). U.S. rice production is grown in three major states; Arkansas, California, and Louisiana. There are many lakes in Iowa, Minnesota, and Wisconsin that have had outbreaks of HPAI. Since the beginning of 2015, HPAI has resulted in the loss of more than thirty million layers and pullets 


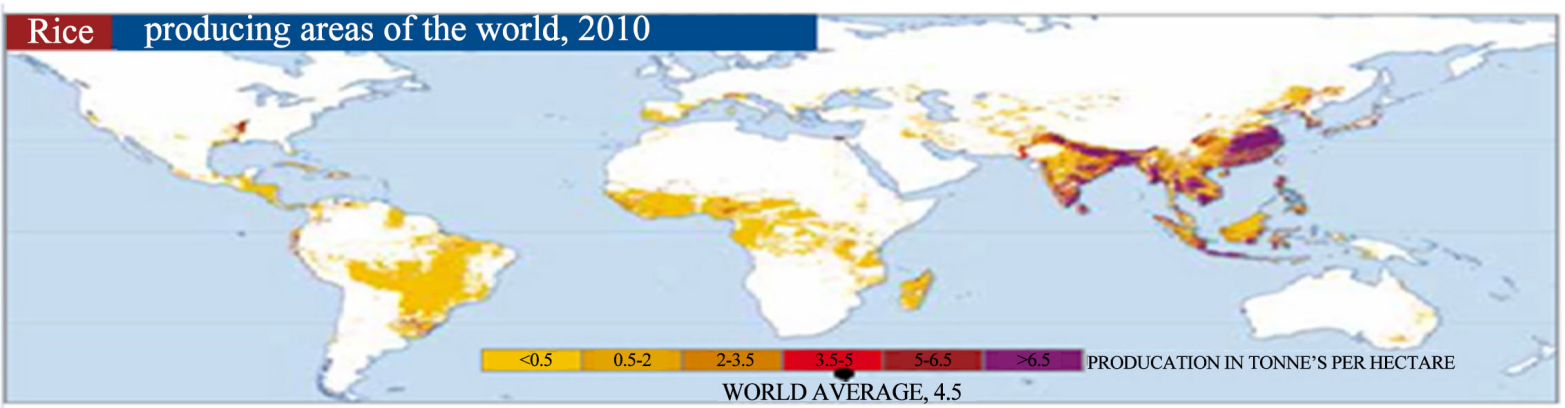

(a)

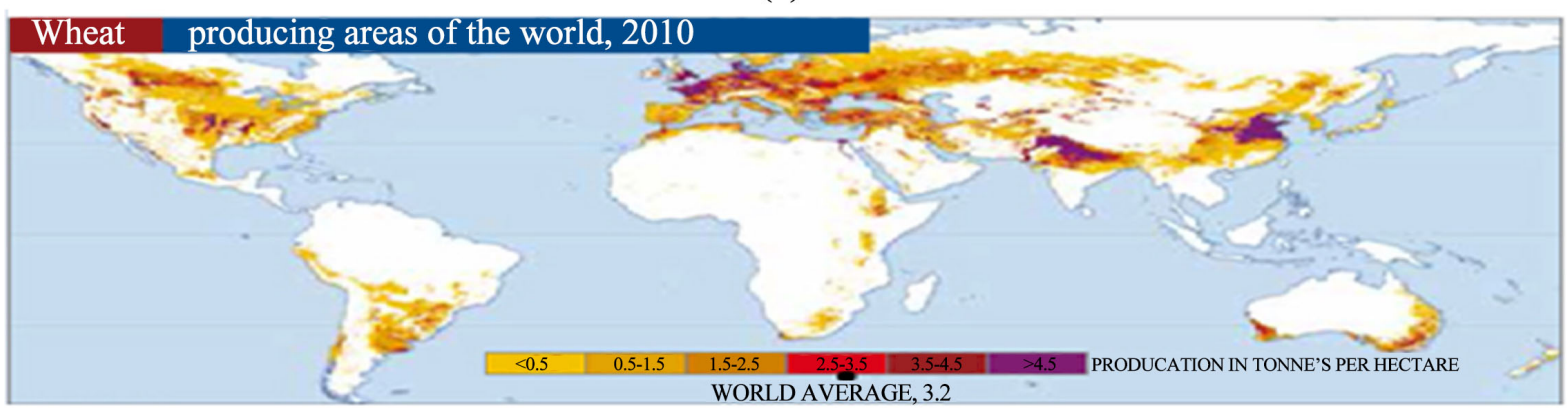

(b)

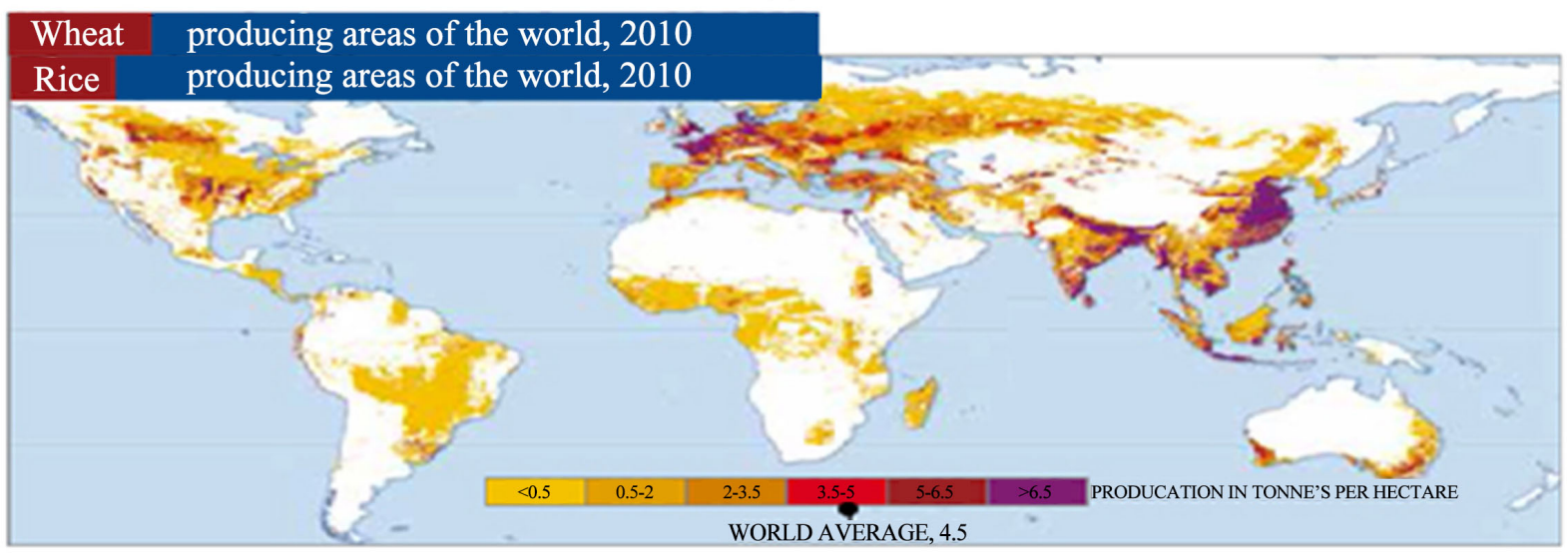

(c)

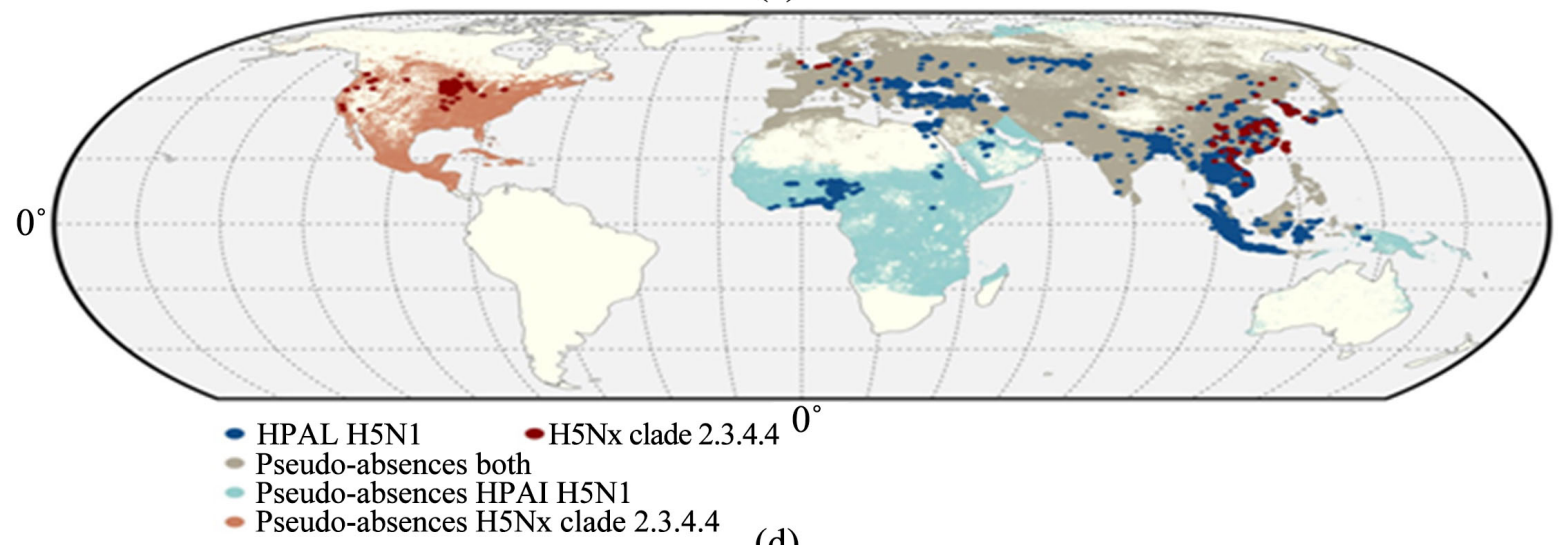

(d)

Figure 9. (a) Rice and (b) wheat producing areas of the world, 2010 (Food and Agriculture Organization of the United Nations) along with (c); the superimposed map with rice and wheat together while (d); the map of HPAI H5N1 outbreak [22] is compared for its similarity with that of (c). 


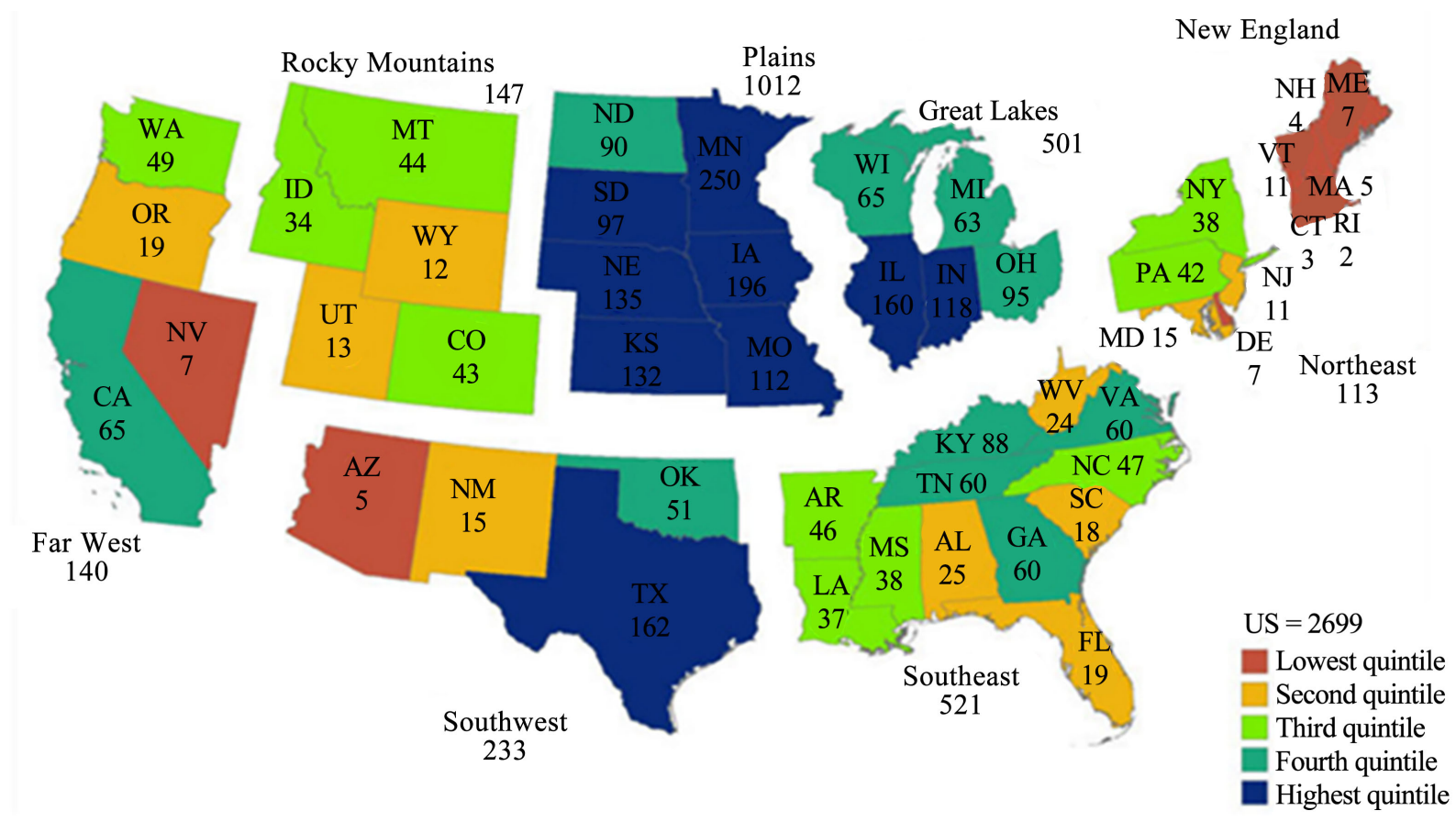

Figure 10. Modeled number of AIV cases in wild birds by state, 2000-2008 [29].

and 1.5 million turkeys in Iowa from infection or depopulation due to exposure to the virus. Layer operations affected by HPAI across the U.S. are in Iowa, Minnesota, Nebraska, Wisconsin, and South Dakota, and represent a significant percentage of pre-outbreak inventories, particularly for Iowa (52\%) and Minnesota (nearly 40\%). Turkey operations in Arkansas, California, Iowa, Minnesota, Missouri, North Dakota, South Dakota, and Wisconsin have seen losses. The most significant losses have been in Iowa, South Dakota, and Minnesota who have lost 15\%,12\% and 10\% of their pre-outbreak inventories, respectively (http://www.poultrymed.com/Infectious-Disease-2015). The map of AIV number (Figure 10) was close to that of cropland with waters in the U.S. Since migratory birds come to cropland to feed on crops (rice, wheat, corn), they can spread LPAI in cropland after contact with wild domestic birds which eventually mutates as HPAI to kill the poultry in the farmhouse. Therefore, HPAI outbreaks (Figure 9(d)) are proportional to percentage cropland (Figure $9(\mathrm{c})$ ).

\section{PREDICTION OF AIV OUTBREAK BY SATELLITE PARAMETERS}

The timing and the location of AIV outbreak is predicted by satellite and ground station data such as desert dusts (Antarctic, Arctic and Continental deserts), climate (temperature, relative humidity, precipitation, wind), migratory birds (species, latency time, flyways), ozone hole size (UV radiation), average daily sunspot number (10.7 cm solar flux), water (river, lake, reservoir, mudflat, pond), fish (mudfish, catfish, lungfish, bullfrog), and crops (rice and wheat). Table 3 shows the outbreak of AIV with various strain, year, country as a function of year of minimal average daily sunspot area. The relationship between the year of AIV outbreak was strongly correlated $\left(\mathrm{R}^{2}=0.9967\right)$ with the year of minimal average daily sunspot area, as shown in Figure 11. The location of AIV outbreak is determined by parameters such as crops, migratory birds, desert dust, climate, and low UV radiation.

The increases of global atmospheric $\mathrm{CO}_{2}$ or temperature induce the increase of UV radiation due to the decrease of ozone holes in the Poles. Such a climate change provides the strong UV radiation to cause the mutant AIV in the Poles for the AIV outbreaks in the Continents.

Since the global carbon dioxide emissions increase continuously in the Earth, the control parameter is then the minimal sunspot number or the $10.7 \mathrm{~cm}$ solar flux for the onset of mutant AIV in the Poles to be 
transmitted via migratory birds for HPAI outbreaks in the poultry and humans. The minimum sunspot number (minimal average daily sunspot area) or the $10.7 \mathrm{~cm}$ solar flux is the indicator of AIV outbreaks in the Continents a few months ahead of migratory birds with mutant AIV in the Poles.

Specifically, satellite data showing the maximal ozone depletion in the Arctic and the Antarctic induce the extensive UV radiation causing the onset of mutant AIV in the North and South Poles. Early warning of Continental AIV outbreaks at the poultry farmhouses and humans can be based on satellite data.

The ice-melting in Antarctica induces the low salinity with less algal and krill in the Antarctic Peninsula, which is a preferred environment to infect penguins with AIV. Penguins are a group of aquatic and flightless bird. Since krill feeding algae is the major prey of penguin, lack of krill immunity to AIV via infected virus, bacteria, and algae can cause LPAIV in penguins to be transmitted by migratory birds for ultimate spreading LPAIV in Continents. Low pathogenic avian influenza (LPAI) viruses are naturally occurring in wild birds such as ducks, geese, swans, and gulls. These viruses generally do not cause illness in wild birds. However, when spread to poultry they can be highly pathogenic avian influenza (HPAI) and cause illness and death in commercial farms [23]. It is therefore important to predict the outbreak of AIV in Continents by satellite observation of ice-melting in Antarctica, especially in the Antarctic Peninsula. Table 4 implies the degree of damage by AIV outbreak in the Continents with satellite parameters of independent variables $\left(\mathrm{CO}_{2}\right.$, minimum sunspot number $)$, dependent variables $\left(\mathrm{O}_{3}, \mathrm{UV}\right.$, temperature, ice-melting, algae, krill).

Table 3. Year of minimal average daily sunspot area with the year of outbreak of AIV during 1878 to 2016.

\begin{tabular}{|c|c|c|}
\hline $\begin{array}{l}\text { Year of minimal average } \\
\text { daily sunspot area }\end{array}$ & $\begin{array}{c}\text { Outbreak of AIV } \\
\text { (Strain, Year, Country) }\end{array}$ & Reference (Year) \\
\hline 1878 & 1878, Italy & [31] (1878) \\
\hline 1890 & HPAI, 1894 & [32] (1926) \\
\hline 1902 & HPAI, 1901 & [33] (1975) \\
\hline 1914 & HPAI H1N1, 1918, Spain & [34] (2008) \\
\hline 1924 & LPAI H6N2, 1924-1925, USA & [35] (2017) \\
\hline \multicolumn{3}{|l|}{1934} \\
\hline \multicolumn{3}{|l|}{1945} \\
\hline 1955 & $\begin{array}{l}\text { HPAI H2N2, 1957, Hong Kong/H5N3, 1961, South } \\
\text { Africa/H5N1, 1959, Scotland }\end{array}$ & [36] (1955) \\
\hline 1966 & HPAI H5N9, 1966, Ontario/H3N2, 1968, Hong Kong & [37] (2000) \\
\hline 1976 & $\begin{array}{c}\text { HPAI H7N7, 1976, Australia/ } \\
\text { H1N1, 1979, Europe/Germany and England }\end{array}$ & [37] (2000) \\
\hline 1984 & $\begin{array}{l}\text { HPAI H5N2, 1983-1984, Pennsylvania/ } \\
\text { H5N8, 1983, Ireland/H7N3, 1985, Australia }\end{array}$ & [38] (2011) \\
\hline 1995 & HPAI H5N1, China, 1994, 1996, 1997/H5N2, 1994, Mexico & \\
\hline 2006 & $\begin{array}{c}\text { HPAI H7N3, 2004, Canada/H5N2, 2004, Texas and South } \\
\text { Africa/H7N7, 2005, Korea/H5N1, 2005, China/H5N3, 2007, } \\
\text { Canada/H5N8, 2010, East Asia, Europe, North America/HPAI } \\
\text { H5N1, 2005, 2006, Eurasia }\end{array}$ & [38] (2011) \\
\hline 2016 & LPAI H11N2, Antarctica, 2013/H5N5, Antarctica, 2015 & \\
\hline
\end{tabular}

Note: 1) [12]. 2) [30]. 
Table 4. Satellite parameters of independent and dependent variables for various degrees of damage by AIV outbreak in the Continents.

\begin{tabular}{|c|c|c|c|c|c|c|c|c|c|}
\hline \multicolumn{2}{|c|}{ AI Virus } & \multicolumn{8}{|c|}{ Satellite Parameter ( $\uparrow$; increase, $\downarrow$; decrease) } \\
\hline & & \multicolumn{2}{|c|}{ Independent } & \multicolumn{6}{|c|}{ Dependent } \\
\hline $\begin{array}{l}\text { Degree of } \\
\text { Damage }\end{array}$ & $\begin{array}{l}\text { Degree of } \\
\text { AIV } \\
\text { Mutation }\end{array}$ & $\mathrm{CO}_{2} \uparrow$ & $\begin{array}{l}\text { Minimum } \\
\text { Sunspot } \\
\text { Number } \downarrow\end{array}$ & $\mathrm{O}_{3} \downarrow$ & $\mathrm{UV} \uparrow$ & $\underset{\uparrow}{\text { Temperature }}$ & $\begin{array}{c}\text { Ice-Melting } \\
\uparrow\end{array}$ & Algae $\downarrow$ & Krill $\downarrow$ \\
\hline 1) $\operatorname{High}(\bullet)$ & $\bullet$ & $\bullet$ & $\bullet$ & $\bullet$ & $\bullet$ & $\bullet$ & $\bullet$ & $\bullet$ & $\bullet$ \\
\hline 2) Middle (@) & (-) & (-) & (-) & (-) & (-) & (-) & (-) & (-) & (0) \\
\hline 3) Low (०) & ० & o & ○ & o & o & o & o & o & o \\
\hline
\end{tabular}

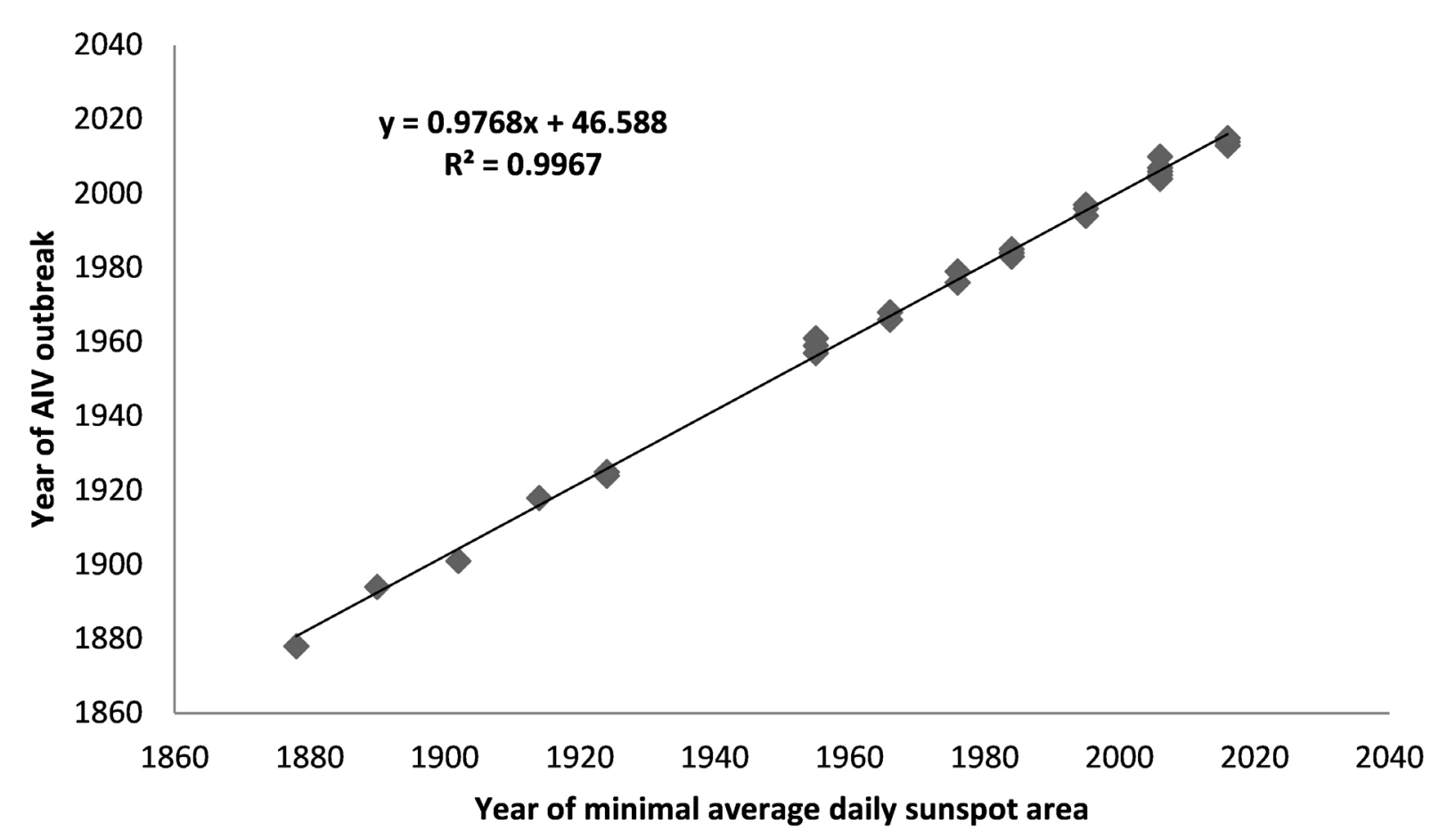

Figure 11. Relation between the year of AIV outbreak and the year of minimal average daily sunspot area (minimum sunspot number) during 1878 to 2016 with high linearity $\left(R^{2}=0.9967\right)$.

The highest degree of damage by AIV outbreak in the Continents can be caused by the highest degree of AIV mutation when $\mathrm{CO}_{2} \uparrow$, minimum sunspot number $\downarrow$ or $10.7 \mathrm{~cm}$ solar flux $\downarrow, \mathrm{O}_{3} \downarrow$, UV $\uparrow$, temperature $\uparrow$, ice-melting $\uparrow$, algae $\downarrow$, and krill $\downarrow$. Since all of these satellite parameters are correlated to each other, the degrees of AIV outbreak and mutation with real time remote sensings of these satellite parameters can be predicted a few months ahead due to duration of migratory birds flights with mutant AIV from Poles prior to AIV outbreak in the Continents for proper preparedness of AIV damage to poultry farmhouses and humans.

Sunspots change through an average cycle of 11 years with 14 months standard deviation. Ultraviolet radiation increases dramatically during high sunspot activity. The converse is true during minimum sunspot activity (https://www.weather.gov/fsd/sunspots). Sunspot dynamics were reflected in human phy- 
siology and pathophysiology [39]. The $10.7 \mathrm{~cm}$ solar flux is the disc-integrated emission from the sun at the radio wavelength of $10.7 \mathrm{~cm}(2800 \mathrm{MHz})$ while $10.7 \mathrm{~cm}$ solar flux is highly correlated $\left(\mathrm{r}^{2}=0.990\right)$ with the International Sunspot Number [12]. When $10.7 \mathrm{~cm}$ flux was minimal in Antarctica with high UV-B radiation in 1996, there were AIV outbreaks at Continents in $1996.10 .7 \mathrm{~cm}$ solar flux is a measure of the activity of the sun with values 186.45 in 1990, 82.66 in 1994, 74.20 in 1995, 71.06 in 1996, 75.75 in 1997, 117.03 in 1998, 157.87 in 1999, as shown in Figure 12. Since $10.7 \mathrm{~cm}$ solar flux showed the lowest value in 1996 in Figure 12 there were correspondingly AIV at Guangdong in China in 1996 and a spread of H5N1 worldwide in 1997.

Low values of $10.7 \mathrm{~cm}$ solar flux in Figure 12 mean the low sunspot number with high UV radiation due to thin ozone hole size. Under high solar activity there is an extremely high UV radiation to sterilize totally all the viruses in the Poles. Only under high solar activity or low sunspot area, high UV radiation is available in Poles enough to cause the mutant virus or mutant AIV via penguins in Antarctica and guillemot (great auk, razorbill) in Arctica, which are in contact with migratory birds to spread mutant AIV throughout the Continents.

The sunspot number showed the minimal value in 2009 and 2010 in Figure 4, which might have the maximal UV radiation to cause the mutant AIV strain from H5N1 such as H5N8 and H5N6.

The Arctic ozone hole showed the lowest level for March 2011

(http://www.theozonehole.com/arcticozone.htm). Correspondingly, there were the outbreaks of AIV in Canada (H5N2, turkey, 2009, 2010; H1N1, turkey, 2009), in USA (H5N3, turkey, 2009; H5N2, chicken, 2010; H7N3, turkey, 2011; H7N9, chicken, turkey, goose, guinea fowl, 2010; H1N1, turkey, 2010), and in Mexico (H5N2, chicken, 2009, 2010, 2011). It can be concluded that the lowest level of the Arctic ozone hole in 2011 and minimal sunspot number in 2009 and 2010 might induce the outbreaks of AIV in the North America during 2009 to 2011. AIV was observed in Europe (Germany, UK, Austria, Croatia, Italy, Greece, Romania, Bulgaria, Ukraine, Russia), Asia (Israel, Gaza, Cyprus, Jordan, Iran, Iraq, Kuwait, Turkey, Saudi Arabia, Pakistan, Afghanistan, Kazakhstan, India, Thailand, Cambodia, Vietnam, Laos, Bangladesh, Indonesia, Malaysia, China, South Korea, Japan), and Africa (Nigeria, Ivory Coast, Burkina Faso, Togo, Ghana, Cameroon, Niger, Egypt, Sudan, Djibouti), where there are crops (rice and wheat), waters, desert dust, low UV radiation, and migratory birds. It may be possible to predict the timing and the location of the AIV outbreak via satellites and ground stations with parameters shown in Figure 13.

There was an abrupt $2 \%$ rise of global $\mathrm{CO}_{2}$ emissions in 2017 [40] as well as the minimum sunspot number in 2018 (Figure 14). Outbreaks of AIV with the highest degree of damage are thus expected from November 2018 till April 2019 in North America, East Asia, China, South Korea, Japan, west Africa, and Europe.

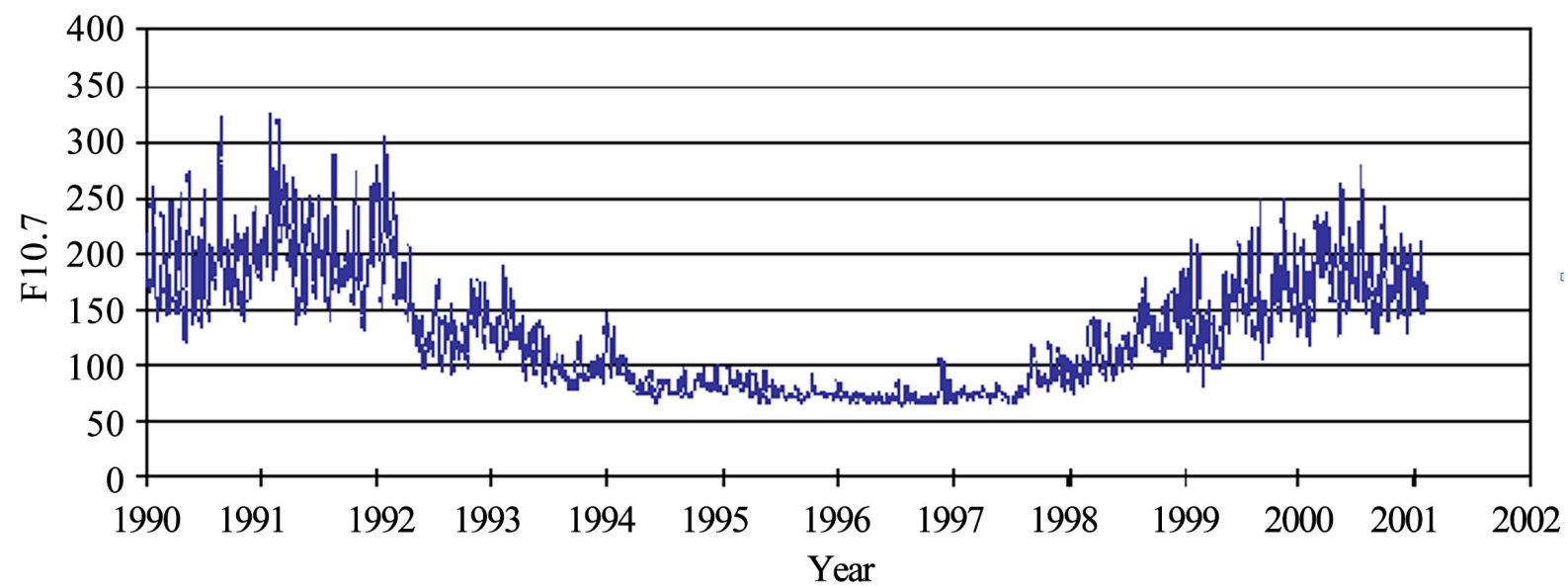

Figure 12. Solar flux $10.7 \mathrm{~cm}$ Antarctica 1990-2000. 


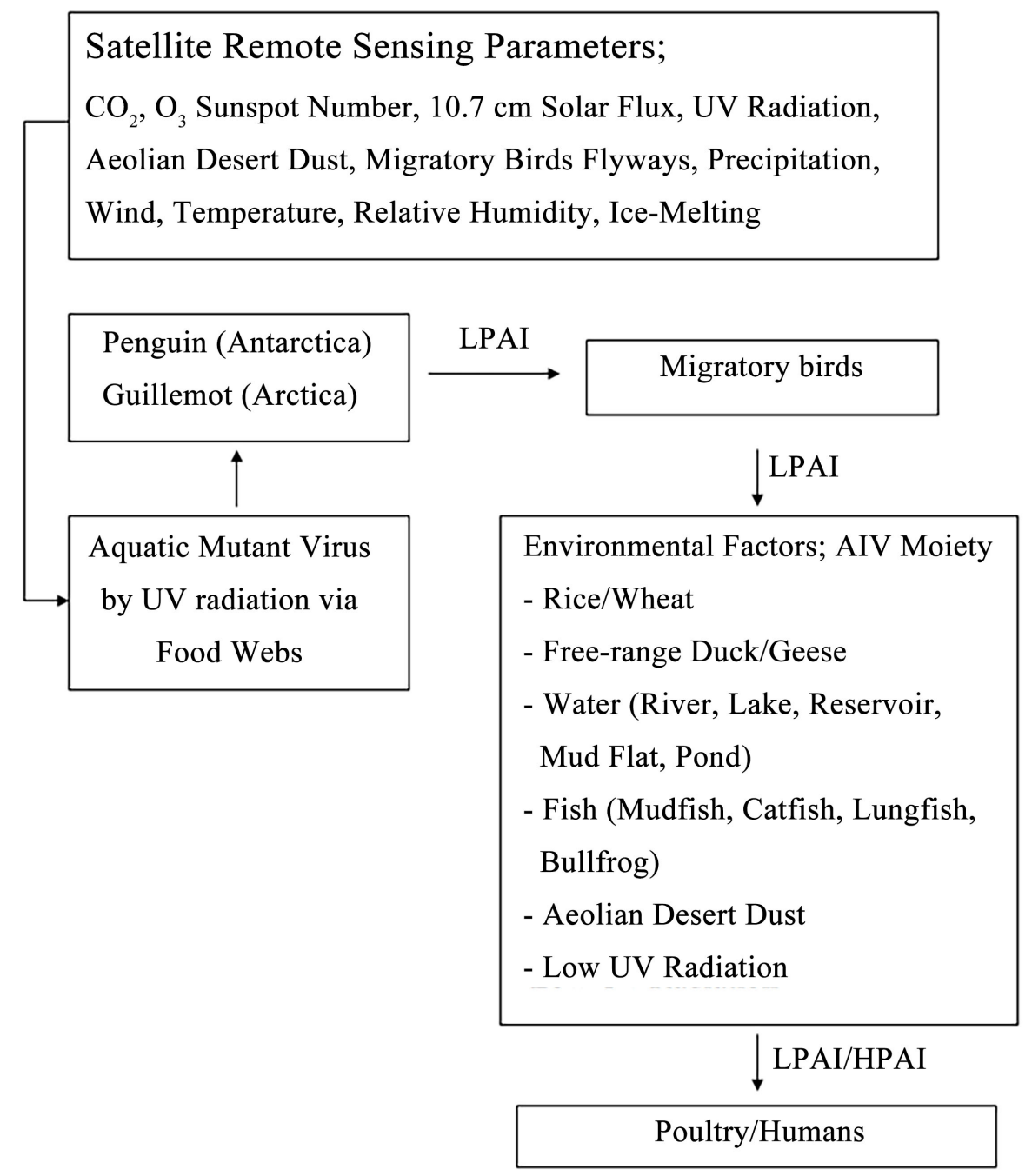

Figure 13. Sequential flow diagram satellite remote sensing parameters for prediction of time and region in AIV outbreak.

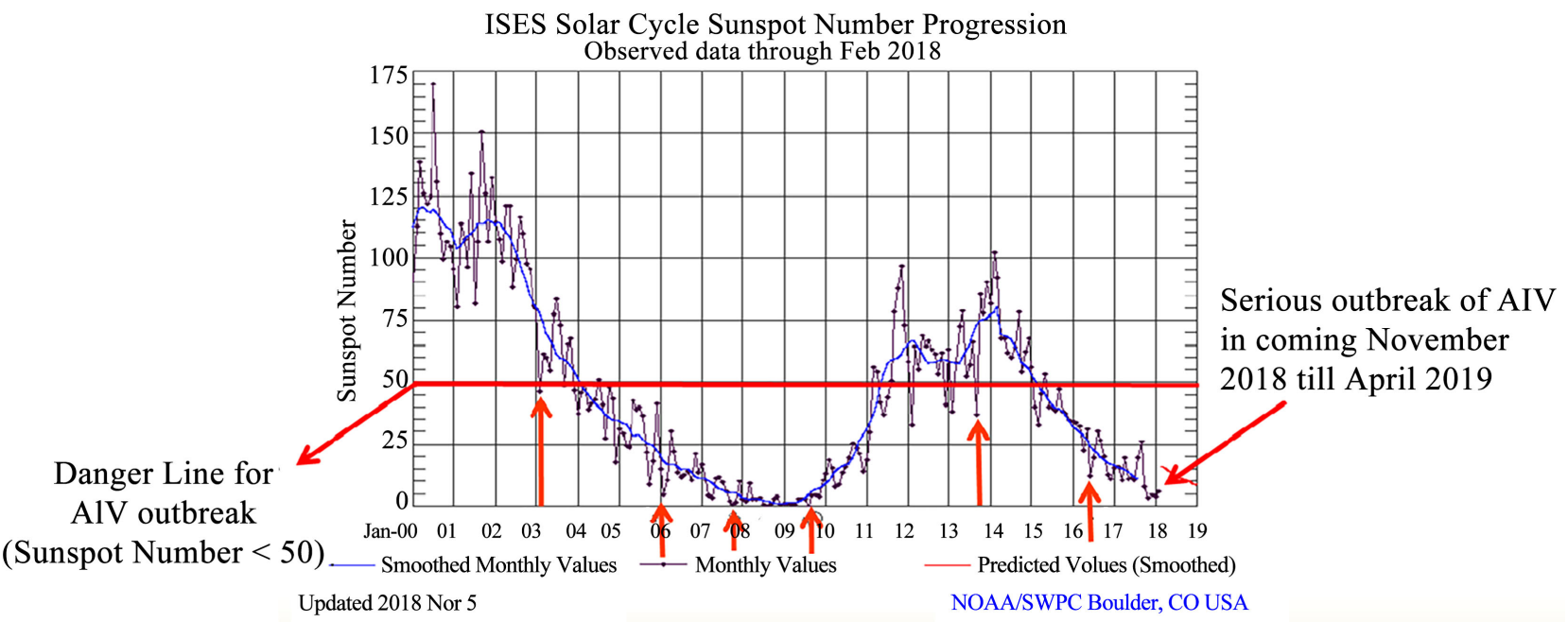

Figure 14. Sunspot number prediction (2016/10) [41] for prediction of AIV outbreaks. 
Recent AIV outbreaks in South Korea were summarized in Table 5 to show that AIV occurred when sunspot numbers were below 50, as indicated in arrows in Figure 14.

It is suggested that the increase of $\mathrm{CO}_{2}$ induces a sequentially thin ozone hole, increases of air temperature in Antarctica, UV radiation, and finally mutant AIV, the latter being transmitted from Poles to Continents via migratory birds for HPAI AIV outbreaks in Continents in favorable environments. Crucially, the Second Industrial Revolution is generally dated between 1870 and 1914 (Wikipedia, 2018) while the first HPAI occurred in Italy in 1878 [32] and the 1918 pandemic Spanish flu from January 1918 to December 1920 resulted in the deaths of 50 to 100 million as one of the deadliest natural disasters in human history [34]. It is postulated that $\mathrm{CO}_{2}$ increase since the start of The Second Industrial Revolution might ultimately induce AIV outbreaks in the Continents. This is a remarkable discovery to find out the initiative relation between AIV outbreak and the climate change induced by $\mathrm{CO}_{2}$ increases. To avoid the AIV outbreaks in poultry farmhouse, the use of artificial UV radiation through multiple UV lamps are simply suggested making contact with clean indoor air and drinking water qualities via inactivation of AIV through viral DNA destruction by artificial UV light $(254 \mathrm{~nm})$.

The 11-year cycle of solar activity with a standard deviation of about 14 months is characterized by the rise and fall in the numbers and surface area of sunspots. Increased solar activity includes increases in extreme ultraviolet and X-ray emissions from the Sun which produce dramatic effects in the Earth's upper atmosphere. Sunspots (dark patches on the Sun where intense magnetic fields loop up through the surface from the deep interior) discovered in 1844 . The $10.7 \mathrm{~cm}$ solar flux is the disk integrated emission from the Sun at the radio wavelength of $10.7 \mathrm{~cm}(2800 \mathrm{MHz})$. This measure of solar activity has advantages over sunspot numbers and areas in that it is completely objective and can be made under virtually all weather conditions [12]. Indicator of the level of solar activity is the flux of radio emission from the Sun at a wavelength of $10.7 \mathrm{~cm}(2.8 \mathrm{GHz}$ frequency). This flux has been measured daily since 1947. It is an important indicator of solar activity because it tends to follow the changes in the solar UV radiation that influences the Earth's upper atmosphere and ionosphere. $10.7 \mathrm{~cm}$ follows the sunspot number quite closely and similar prediction techniques can be used (http://solarscience.msfc.nasa.gov/predict.shtml). Decreased solar activity may decrease UV radiation enough to endure the persistence of AIV in the Poles while increased solar activity may produce extensive UV to sterilize and inactivate AIV itself. Therefore, it is expected there are negligible outbreaks of AIV during maximal peaks, as shown in 1990 and 1991, 2001, 2013 from Figure 4 and Table 3.

According to Planck-Einstein relation [42],

$$
E=h f
$$

where $h=$ Planck constant

$f=$ frequency $=c / \lambda$

$c=$ speed of light

$\lambda=$ wavelength of light

$$
E=h c / \lambda
$$

Energy is expressed by heat $(Q)$ as,

$$
Q=m C_{p} \Delta T
$$

where $m=$ mass

$C_{P}=$ heat capacity

$\Delta T=$ temperature difference

Assuming the reference temperature is zero, then

$$
Q=m C_{p} T
$$

Combining (2) and (3),

$$
E=(h c)\left(m C_{P}\right)(T / \lambda)=C(T / \lambda)
$$


where $C=(h c)\left(m C_{P}\right)=$ constant .

Increase of global $\mathrm{CO}_{2}$ emissions induce a thin ozone layer for extensive UV radiation. Equation 4 implies that energy $(E)$ is increased as intensity of UV radiation with low wavelength $(\lambda)$ (increases to have the increase of hydroxyl layer temperature $(T)$, as shown in Figure 15.

The ability to use the Hydroxyl layer to measure the temperature in the Antarctic mesosphere, makes the $\mathrm{OH}$ spectrometer an ideal instrument for monitoring middle-atmosphere temperatures for studies of climate change (Climate change in the mesosphere, www.antarctica.gov.au).

Figure 15 is analogous to the ultraviolet distribution since temperature is increased as UV is extensive. The cyclic pattern is exactly opposite to that of the average sunspot areas. During the minimum of the sunspot area, temperature profile showed the maximum value due to extensive UV radiation, which enhances the mutation of AIV in the Poles. That is, the peak temperature period corresponds to the minimal sunspot area, the latter providing the maximal UV radiation. Satellite parameters for AIV outbreaks are summarized in Figure 16.

The degree of the sunspot number can be a good indicator of AIV outbreak.

There are three cases of AIV outbreak depending upon the sunspot number and the intensity of UV radiation in the Continents, as summarized in Table 6.

Table 5. Recent outbreaks of AIV in South Korea.

\begin{tabular}{ccccccc}
\hline Year & 2003/2004 & 2006/2007 & 2008 & 2010/2011 & 2014/2015 & 2016/2017 \\
\hline Season & Winter & Winter & Spring & Winter & Winter & Winter \\
Culling (million) & 5.3 & 2.8 & 10.2 & 6.5 & 19.4 & 37.9 \\
Strain Type & H5N1 & H5N1 & H5N1 & H5N1 & H5N8 & H5N8, \\
$\begin{array}{c}\text { Money paid } \\
\text { to farmer }\end{array}$ & 87.4 & 33.9 & 181.7 & 80.7 & 238.1 & 257 \\
$\begin{array}{c}\text { (US million dollars) } \\
\text { Sunspot Number }\end{array}$ & 45 & 5 & 0 & 5 & 40 & 10 \\
\hline
\end{tabular}

Table 6. Prediction for the outbreak of AIV depending upon the sunspot number and the intensity of UV radiation.

\begin{tabular}{ccccc}
\hline Case & Sunspot Number & ${ }^{*}$ Intensity of & ${ }^{* \star}$ Outbreak & Applicable Regions \\
\hline 1 & $\lim _{\text {Sun } \rightarrow \text { Min }}$ AIV $=1$ & Low & Yes (1) & $\begin{array}{c}\text { North America, East Asia, west Africa, Europe, } \\
\text { South Korea, China, Japan }\end{array}$ \\
& $\lim _{\text {Sun } \rightarrow \text { Max }}$ AIV $=0$ & Low & No (0) & $\begin{array}{c}\text { North America, East Asia, west Africa, Europe, } \\
\text { South Korea, China, Japan }\end{array}$ \\
3 & $\lim _{\text {Sun } \rightarrow \text { Min }}$ AIV $=0$ & High & No (0) & $\begin{array}{l}\text { New Zealand, Australia, southern South } \\
\text { America, southern Africa, Scandinavian } \\
\text { countries, Denmark, northern Russia, and } \\
\text { northern Canada }\end{array}$ \\
\end{tabular}

Notes; 1 : Sun $=$ Sunspot number. Min $=$ Minimal sunspot number. AIV $=$ Outbreak of AIV. ${ }^{\star \star} 1=$ Significant outbreak of AIV. 2: Max = Maximal sunspot number. ${ }^{* *} 0=$ Negligible outbreak of AIV. $3:{ }^{* *} 0=$ Negligible outbreak of AIV with skin cancers. ${ }^{*}$ : Low or high UV radiation. 


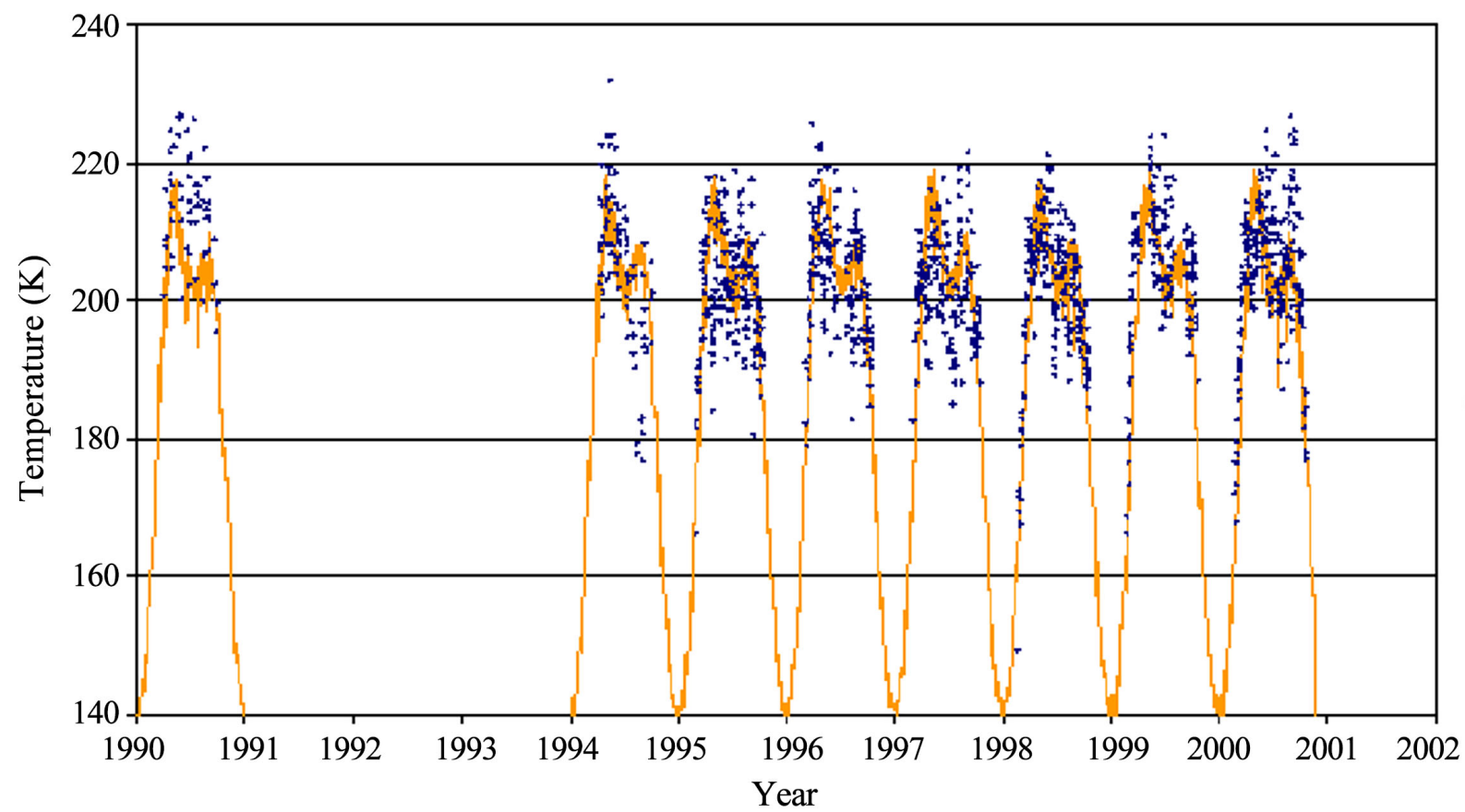

Figure 15. Daily average hydroxyl layer temperatures from 1990 to 2000 [43].

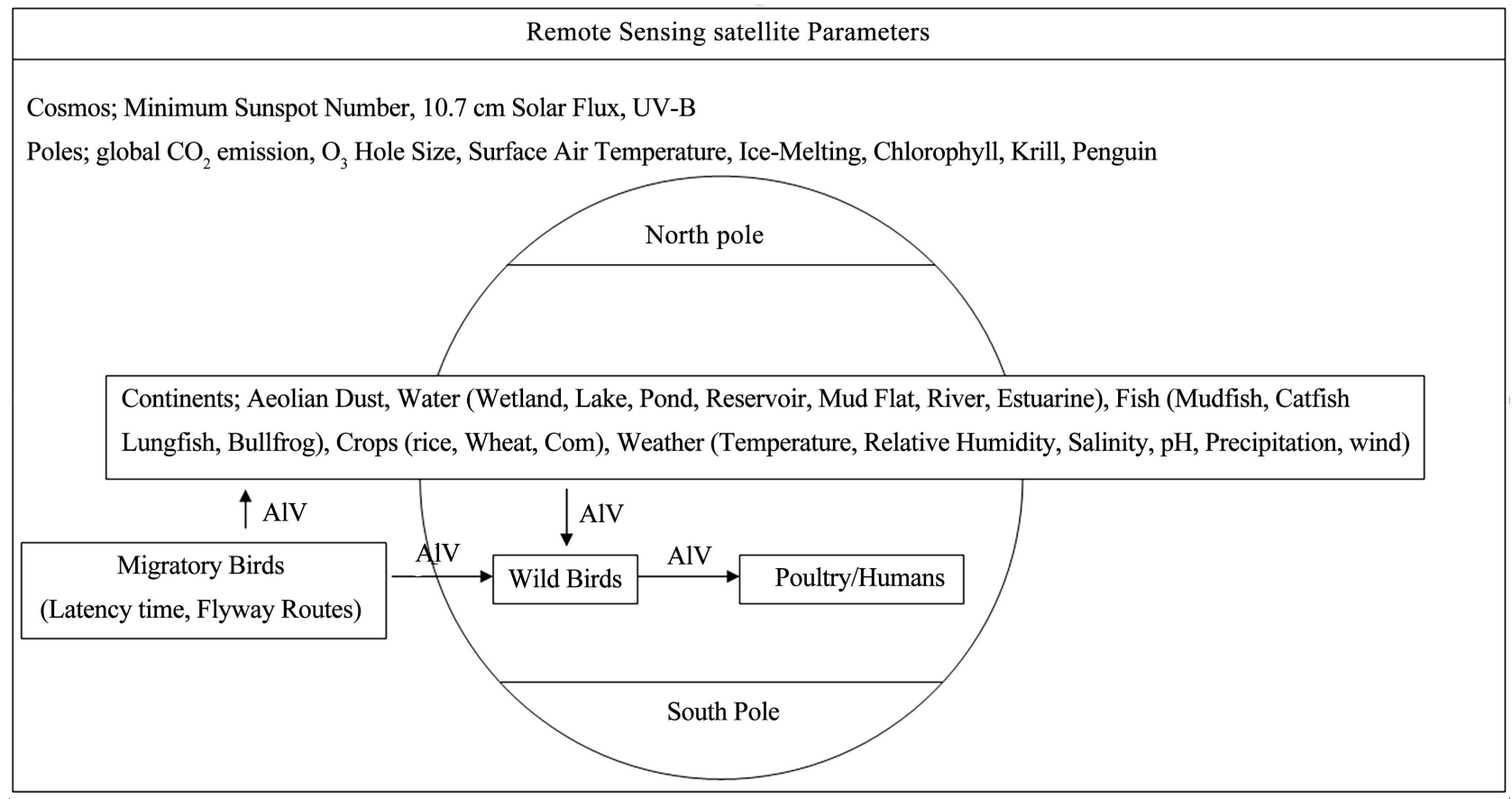

Figure 16. Schematic diagram of satellite parameters around the Earth associated with AIV outbreaks.

\section{CONCLUSIONS}

The present study showed that AIV occurred in the regions with rice and wheat productions under low UV radiation while there were negligible AIV outbreaks in the regions with a high rate of skin cancer due to extensive UV radiation. It is therefore proposed that artificial UV radiation in poultry farmhouses 
is a simple solution to suppress AIV outbreaks. Furthermore, AIV outbreaks can be predicted a few months in advance by remote sensing satellite parameters such as Cosmos (minimum sunspot number, $10.7 \mathrm{~cm}$ solar flux, UV radiation), Poles $\left(\mathrm{CO}_{2}, \mathrm{O}_{3}\right.$ hole, hydroxyl layer temperature, ice-melting, chlorophyll or algae, krill, penguin, guillemot), and Continents (migratory birds, Aeolian dust, UV radiation, waters, fish, rice and wheat, climate). Since there was an abrupt $2 \%$ rise of global $\mathrm{CO}_{2}$ emissions in 2017 , while the minimum sunspot number is reached at the end of 2018 , there can be extensive UV radiation for mutant AIV in the Poles to have the highest degree of damage by AIV in regions such as U.S., East Asia, China, South Korea, Japan, West Africa, and Europe from November of 2018 till April of 2019. However, low damages by AIV are expected in regions such as Australia, New Zealand, Scandinavian countries, and South America due to extensive UV radiation induced by thin ozone layers from the Poles.

\section{ACKNOWLEDGMENTS}

The author expresses sincere gratitude to G-LAND and the University of Suwon of South Korea for their financial support.

\section{CONFLICTS OF INTEREST}

The authors declare no conflicts of interest regarding the publication of this paper.

\section{REFERENCES}

1. Centers for Disease Control and Prevention (2017) Influenza Type A Viruses. National Center for Immunization and Respiratory Diseases (NCIRD).

2. Al-Shekaili, T., Baylis, M. and Ganapathy, K. (2015) Molecular Detection of Infectious Bronchitis and Avian Metapneumoviruses in Oman Backyard Poultry. Research in Veterinary Science, 99, 46-52. https://doi.org/10.1016/j.rvsc.2014.12.018

3. World Organization for Animal Health (2015).

4. Keeler, S.P., Berghaus, R.D. and Stallknecht, D.E. (2012) Persistence of Low Pathogenic Avian Influenza Viruses in Filtered Surface Water from Waterfowl Habitats in Georgia, USA. Journal of Wildlife Diseases, 48, 999-1009. https://doi.org/10.7589/2011-11-314

5. Sutton, et al. (2013) Inactivation of the Infectivity of Two Highly Pathogenic Avian Influenza Viruses and a Virulent Newcastle Disease Virus by Ultraviolet Radiation. Avian Pathology, 42, 566-568. https://doi.org/10.1080/03079457.2013.853867

6. McDevitt, J.J., Rudnick, S.N. and Radonovich, L.J. (2012) Aerosol Susceptibility of Influenza Virus to UV-C Light. Applied and Environmental Microbiology, 78, 1666-1669. https://doi.org/10.1128/AEM.06960-11

7. World Health Organization (2004) Age-Standardised Death Rates from Melanoma and Other Skin Cancers by Country (per 100,000 Inhabitants). Lokal_Profil (12 November 2009) Vector Map from BlankMap-World6.

8. Skerratt, J.H., Davidson, A.D., Nichols, P.D. and McMeekin, T.A. (1998) Effect of UV-B on Lipid Content on Three Antarctic Marine Phytoplankton. Phytochemistry, 49, 999-1007. https://doi.org/10.1016/S0031-9422(97)01068-6

9. Dulermo, R., Fochesato, S., Blanchard, L. and De Groot, A. (2009) Mutagenic Lesion by Pass and Two Functionally Different RecA Protein in Deinococcus desrti. Molecular Microbiology, 74, 194-208. https://doi.org/10.1111/j.1365-2958.2009.06861.x

10. Zhou, et al. (2013) Baiji Genomes Reveal Low Genetic Variability and New Insights into Secondary Aquatic Adaqtions. Nature Communications, 4, 2708. https://doi.org/10.1038/ncomms3708

11. Chen, J.Y., Zhou, L.Z., Zhou, B., Xu, R.X., Zhu, W.Z. and Xu, W.B. (2011) Seasonal Dynamics of Wintering 
Waterbords in Two Shallow Lakes along Yangtze River in Anhui Province. Zoological Research, 32, 540-548.

12. Hathaway, D.H. (2010) The Solar Cycle. Living Reviews in Solar Physics, 7, 1.

https://doi.org/10.12942/lrsp-2010-1

13. Hurt, et al. (2016) Evidence for the Introduction, Reassortment and Persistence of Diverse Influenza A Viruses in Antarctica. Journal of Virology, 90, 9674-9682. https://doi.org/10.1128/JVI.01404-16

14. Griffin, A. (2017) Thousands of Tiny Baby Adelie Penguin Starve to Death as Changing Weather Forces Parents to Travel for Food.

15. Slezak, M. (2017) Penguin Disaster as Only Two Chicks Survive from Colony of 40,000. The Guardian.

16. Jiménez-Espejo, et al. (2014) Saharan Aeolian Input and Effective Humidity Variations over Western Europe during the Holocene from a High Altitude Record. Chemical Geology, 374-375, 1-12.

17. Yamaguchi, N., Ichijo, T., Sakotani, A., Baba, T. and Nasu, M. (2012) Global Dispersion of Bacterial Cells on Asian Dust. Scientific Reports, 2, Article No. 525. https://doi.org/10.1038/srep00525

18. Muzaffar, S.B., Takekawa, J.Y., Prosser, D.J., Newman, S.H. and Xiao, X. (2010) Rice Production Systems and Avian Influenza: Interactions between Mixed-Farming Systems, Poultry and Wild Birds. Waterbirds, 33, 219-230. https://doi.org/10.1675/063.033.s116

19. Micheletti, M.I., et al. (2003) Sensitivity of Biologically Active UV Radiation to Stratospheric Ozone Changes: Effects of Action Spectrum Shape and Wavelength Ranges. Photochemical \& Photobiological Sciences, 78, 456-461.

20. Richter, R. (2005) Mission to Chile Offers Relief to Skin Cancer Victims. Stanford News.

21. Morrisette, P.M. (1989) The Evolution of Policy Responses to Stratospheric Ozone Depletion. Natural Resources Journal, 29, 793-820.

22. Dhingra, M.S., et al. (2016) Global Mapping of Highly Pathogenic Avian Influenza $\mathrm{H}_{5} \mathrm{~N}_{1}$ and $\mathrm{H}_{5} \mathrm{~N}_{\mathrm{x}}$ Clade 2. 3. 4. 4. Viruses with Sptial Cross-Validation. eLife, 5, e19571.

23. Troshichev, C. and Gabis, I. (2005) Effect of Solar UV Irradiation on Dynamics of Ozone Hole in Antarctic. Journal of Atmospheric and Solar Terrestrial Physics, 67, 93-104. https://doi.org/10.1016/j.jastp.2004.07.020

24. Alvarez-Madrigal and Perez-Peraza (2005) Analysis of the Evolution of the Antarctic Ozone Hole Size. Journal of Geophysical Research Atmosphere, 110, DO2107.

25. Bais, A.F., et al. (2015) Ozone Depletion and Climate Change: Impacts on UV Radiation. Photochemical \& Photobiological Sciences, 14, 19-52. https://doi.org/10.1039/C4PP90032D

26. Ellis, et al. (2004) Investigation of Outbreaks of Highly Pathogenic $\mathrm{H}_{5} \mathrm{~N}_{1}$ Avian Influenza in Waterfowl and Wild Birds in Hong Kong in Late 2002. Avian Pathology, 33, 492-505. https://doi.org/10.1080/03079450400003601

27. Martins, N.R.S. (2012) An Overview on Avian Influenza. Brazilian Journal of Poultry Science, 14, 71-158. https://doi.org/10.1590/S1516-635X2012000200001

28. Childs, N. (2016) Rice Outlook: December 2016. Rice Outlook No. (RCS-16L), 19 p.

29. Fuller, et al. (2010) Mapping the Risk of Avian Influenza in Wild Birds in the US. BMC Infectious Diseases, 10, 187. https://doi.org/10.1186/1471-2334-10-187

30. Lupiani, B. and Reddy, S.M. (2009) The History of Avian Influenza. Comparative Immunology, Microbiology and Infectious Disease, 32, 311-323. https://doi.org/10.1016/j.cimid.2008.01.004

31. Epizoozia, P.E. (1878) A Contagious Disease of Poultry Associated with High Mortality. Annali delP Accademia di Agricoltura di Torino, 21, 87-126.

32. Stubbs, E.L. (1926) Fowl Pest. Journal of the American Veterinary Medical Association, 21, 561-569. 
33. Wilkinson, et al. (1975) 2.2 Spread of $\mathrm{H}_{5} \mathrm{~N}_{1} \mathrm{HPAI}$ in Asia and Beyond. Avian Influenza, Animal Production and Health Division.

34. Trilla, A., Trilla, G. and Daer, C. (2008) The 1918 "Spanish Flu" in Spain. Clinical Infectious Diseases, 47, 668-673. https://doi.org/10.1086/590567

35. Root, J.J., Shriner, S.A., Ellis, J.W., VanDalen, K.K. and Franklin, A.B. (2017) Transmission of $\mathrm{H}_{6} \mathrm{~N}_{2}$ Wild Bird-Origin Influenza A Virus among Multiple Bird Species in a Stacked-Cage Setting. Archives of Virology, 162, 2617-2624. https://doi.org/10.1007/s00705-017-3397-y

36. Schafer, W. (1955) Vergleichende sero-immunologische Untersuchungen über die Viren der Influenza und klassichen Geflügelpest. Zeitschr Natur forschung, 10, 81-91.

37. Matrosovich, et al. (2000) Alterations of Receptor-Binding Properties of H1, H2 and H3 Avian Influenza Virus Hemagglutinins upon Introduction into Mammals. Journal of Virology, 74, 8502-8512. https://doi.org/10.1128/JVI.74.18.8502-8512.2000

38. Prosser, et al. (2011) Wild Bird Migration across the Qinghai-Tibetan Plateau: A Transmission Route for Highly Pathogenic $\mathrm{H}_{5} \mathrm{~N}_{1}$. PLoS ONE, 6, e17622. https://doi.org/10.1371/journal.pone.0017622

39. Hrushesky, et al. (2011) Sunspot Dynamics Are Reflected in Human Physiology and Pathophysiology. Astrobiology, 11, 93-103. https://doi.org/10.1089/ast.2010.0574

40. Carbon Brief (2018) Analysis: Global $\mathrm{CO}_{2}$ Emissions Set to Rise 2\% in 2017 after Three-Year "Plateau".

41. Hathaway, D.H. (2015) The Solar Cycle. Living Reviews in Solar Physics, 12, 4. https://doi.org/10.1007/lrsp-2015-4

42. Richardson, M. (2004) College Physics. McGraw Hill, New York, 864-866.

43. Department of the Environment and Energy (2003) Climate Change in the Mesosphere. Australia's Antarctic Program, Australian Government. 